t J Dev Neurosci. 2016 June ; 51: 50-72. doi:10.1016/j.ijdevneu.2016.04.008. \title{
and clinical research
}

Abstract

\begin{abstract}
or women experiencing depression during pregnancy and postpartum for the past 25 years. SSRIs o SSRIs in utero or as neonates exhibit long-lasting behavioral adaptions. Clinically, children exposed to SSRIs in early life exhibit increased internalizing behavior reduced social behavior, nderlie the deleterious behavioral effects of perinatal SSRI exposure may highlight biologica exposure than others, understanding mechanisms that drive such susceptibility could lead to
\end{abstract}

${ }^{\S}$ Corresponding author at: $17207^{\text {th }}$ Avenue South, SC 745, Birmingham, AL 35294. phone: 205-975-0312, clintons@uab.edu. Publisher's Disclaimer: This is a PDF file of an unedited manuscript that has been accepted for publication. As a service to our customers we are providing this early version of the manuscript. The manuscript will undergo copyediting, typesetting, and review of the resulting proof before it is published in its final citable form. Please note that during the production process errors may be discovered which could affect the content, and all legal disclaimers that apply to the journal pertain. 


\section{Keywords}

serotonin; depression; anxiety; rodent models; SSRI; hippocampus; behavior; neurogenesis; epigenetics

\section{Introduction}

Psychiatric disorders such as depression can have profound, lifelong detrimental effects on an individual's quality of life. According to the Diagnostics and Statistical Manual for Mental Disorders version 5 (DSM-5), an individual meets criteria for major depression if he or she experiences depressed mood or a loss of interest in normally pleasurable activities together with any four of the following symptoms nearly every day for at least two weeks: significant weight loss or weight gain, inability to sleep or oversleeping, psychomotor retardation or agitation, feelings of worthlessness or excessive guilt, diminished concentration, and/or recurring thoughts of death or suicidal ideation [1]. Women are 70\% more likely than men to be diagnosed with depression, with their first depressive episodes often occurring during childbearing years in the teens and young adulthood [2-6].

The monoaminergic theory of depression has dominated psychiatric research for decades, postulating that deficient monoamine (serotonin, norepinephrine, and/or dopamine) concentrations in the brain contribute to the etiology of depression [7-14]. Many depressive symptoms are relieved by drugs that increase synaptic monoamine concentrations [12, 15]. Selective serotonin reuptake inhibitors (SSRIs), which selectively block serotonin reuptake via the serotonin transporter, have been a pharmacological mainstay in the treatment of major depressive disorder for over 25 years. Approximately 10-20\% of pregnant women have been diagnosed with depression and up to $30 \%$ of these women receive SSRI treatment [16-19], which exposes tens of thousands of children annually to serotonin-modulating agents during crucial developmental periods.

A range of biological and environmental factors regulate the developing brain, which sets the stage for an individual's susceptibility to stress and emotional dysfunction in later life [20-23]. The early-life environment plays a major role in shaping an individual's emotional health as brain regions regulating emotion are actively developing from early postnatal life through late adolescence and early adulthood. Maternal mood and quality of caregiving (as well as experiencing childhood neglect or abuse) have long been understood to impact a child's risk for developing psychopathology [24-27]. Studies have also begun to suggest that children exposed to SSRIs in utero are at increased risk for psychopathology, including increased internalizing behavior, abnormal social behavior, and depression during adolescence [28-34].

The long-term effects of SSRIs on human brain development and emotional health beyond the first $\sim 15$ years of life are largely unknown owing to insufficient study; however, in rodents, perinatal SSRI exposure produces a constellation of lifelong behavioral disturbances - increased depression- and anxiety-like behavior, anhedonia, perturbed sleep, diminished sexual performance - that resembles depression in humans [35-45]. Although rodent anxiety- and depression-like behaviors do not completely recapitulate the human 
condition, similar neuroanatomical pathways regulate emotion across species, so perinatal SSRI exposure-induced molecular neuropathology may contribute to perturbed behavioral domains in both rodents and humans. Therefore, rodent studies may offer critical clues to better understand how early life SSRI exposure disrupts brain development and emotional behavior.

This review article has four main objectives. (1) We first give an overview of the development and function of the serotonin system to provide context for how this system may be affected by early life SSRI exposure. (2) We next summarize the clinical outcomes of in utero SSRI exposure in humans as well as (3) the impact of perinatal SSRI exposure on rodent behavior. (4) We conclude with a discussion of neural and molecular mechanisms that may underlie changes in rodent behavior, which may be relevant to neuropathological changes contributing to the deleterious effects of perinatal SSRI exposure on brain and behavior.

\section{Anatomy of the serotonergic system}

Serotonin (5-hydroxytryptamine, 5-HT) neurotransmission requires the presence of numerous molecules, including enzymes required for 5-HT synthesis (Figure 1). Tryptophan hydroxylase 2 (TPH2), the rate-limiting enzyme in 5-HT synthesis, converts tryptophan to 5hydroxytryptophan (5-HTP), which is converted to 5-HT by aromatic L-amino acid decarboxylase (AADC). 5-HT is stored in synaptic vesicles in the presynaptic terminal until an action potential triggers its release into the synaptic cleft where it can activate a variety of postsynaptic receptors (5-HT1-7). One type of 5-HT receptor (5-HT3) is a ligand-gated ion channel, but the remaining receptors are G protein-coupled receptors. 5-HT1 (1A-F) and 5HT5 (5A-B) receptors are Gi/Go-protein coupled receptors that decrease cellular levels of cyclicAMP (cAMP) [46]. The 5-HT2 receptor family (2A-C) are Gq/G11-protein coupled receptors that increase cellular levels of inositol trisphosphate and diacylglycerol. 5-HT4 (4A-B), 5-HT6, and 5-HT7 receptors are Gs-protein coupled receptors that increase cellular levels of cAMP [47]. 5-HTergic action is terminated when it is removed from the synapse via the 5-HT reuptake transporter (SERT) located on the presynaptic neuron [48]. Once 5HT returns to the presynaptic terminal, it can either be repackaged into vesicles for future release, or broken down by monoamine oxidase (MAO).

5-HT in the brain is synthesized by neurons within the raphe nuclei, which are located along the midline throughout much of the rostro-caudal extent of the brainstem [49]. These cells are relatively few in number, totaling about 30,000, but send complex branched axons. 5-HT fibers course throughout the neuraxis to modulate virtually every functional domain of the central nervous system, including affect, cognitive function, and homeostatic processes [50]. The 5-HT system is comprised of nine anatomically distinct cell groups (B1-B9) that are broadly divided into two subdivisions: (a) a rostral division (groups B6-B9), with cell bodies in the midbrain and rostral pons that provide the majority of ascending 5-HTergic fibers that innervate the forebrain; and (b) a caudal division (groups B1-B5) located in the medulla oblongata that send major descending 5-HTergic fibers to the spinal cord [51]. Table 1 defines the cytoarchitectural regions defined as 5-HTergic cell groups B1-9 (based on [51]). 


\subsection{Ascending 5-HT projections}

Fibers emanating from the rostral 5-HTergic cell groups (B6-9) ascend through the medial forebrain bundle to innervate numerous forebrain regions, including the cerebral cortex (particularly layer I), basal ganglia, limbic system, and diencephalon [52-55] (illustrated in Figure 2).The rostral part of the dorsal raphe (RDR) primarily innervates the caudate putamen, as well as the substantia nigra, subthalamic nucleus, substantia innominata, and motor cortex [50]. The ventral part of the dorsal raphe (DRV) predominantly innervates the sensorimotor cortex; it also innervates several cortical regions (motor, frontal, ventrolateral orbital, barrel field, entorhinal corticies and parts of the visual cortex) along with medial septum, several amygdala subnuclei, medial and lateral habenula, and the hypothalamus [50, 56]. The dorsomedial part of the dorsal raphe (DRD) heavily innervates a number of limbic regions associated with stress-response and anxiety, including the medial prefrontal cortex (mPFC), central amygdala, basolateral amygdala, medial amygdala, dorsal hypothalamus, bed nucleus of the stria terminalis (BNST), nucleus accumbens, and dorsolateral periaqueductal grey [50]. The lateral wings of the dorsal raphe (DRVL) project to subcortical regions such as the thalamus, lateral and medial habenula, anterior hypothalamus, periaqueductal grey, and raphe magnus $[50,56]$. The supralemniscal 5HTergic cell group, or B9, is a disperse group of cells that innervate the caudate putamen, lateral and medial septum, medial amygdala, prefrontal and entorhinal cortex, hypothalamus, locus coeruleus, periaquaductral gray (PAG), substantia nigra, median raphe and ventral tegmental area $[56,57]$.

The hippocampus, lateral and medial septum, several midline thalamic nuclei, caudate, entorhinal cortex, hypothalamus, locus coeruleus, and PAG receive projections from the midline portion of the caudal dorsal raphe (DRC) [56]. The intrafascicular part of the dorsal raphe (DRI) innervates the dorsal and ventral hippocampus, entorhinal cortex, and medial septum, as well as several limbic cortical regions (dorsolateral prefrontal cortex, anterior cingulate cortex, and medial orbital cortex) [50]. The median raphe (MnR) innervates the nucleus accumbens, BNST, amygdala, prefrontal cortex, entorhinal cortex, several thalamic nuclei, hypothalamus, and many brainstem regions including the PAG, locus coeruleus, and interpenduncular nucleus [56]. The MnR also provides substantial 5-HTergic innervation to the septohippocampal system given that lesioning of the MnR with 5,7-dihydroxytryptamine (5,7-DHT) reduces hippocampal 5-HT and its major metabolite, 5-hydroxyindolacetic acid (5-HIAA) content by 50-90\% [58, 59]. The MnR sends distinct projections to separate hippocampal layers, including the stratum-lacunosum layer of Ammon's horn, as well as the granule cell layer and inner molecular layer of the dentate gyrus. 5-HTergic efferents to the hippocampus follow four tracts. Efferents from the dorsal raphe follow either the septohypothalamic tract to the lateral septum or the ansa leticularis and perforant path to the hippocampus [50]. Efferents originating from the MnR follow the fimbria-fornix or the cingulum bundle to the septohippcampal system. Most 5-HT fibers in the hippocampus are located within the stratum radiatum and stratum oriens of CA2-3 and the dentate gyrus [50].

\subsection{Descending 5-HT projections}

The caudal 5-HTergic cell groups (B1-5) send dense projections to the spinal cord, with particularly heavy innervation in the dorsal horn (especially lamina I and to a lesser extent 
lamina II), the ventral horn motor nuclei (laminae VIII and IX), the thoracic cord, and intermediolateral column [60, 61]. Collaterals from a single 5-HTergic neuron projecting to the spinal cord can innervate sensory and motor nuclei at different spinal levels [62]. These descending projections serve to regulate the rhythm and coordination of movements [63] as well as the processing of pain [64].The vast majority of all 5-HT axons found in the mammalian spinal cord originate from cells located in the medullary raphe pallidus, raphe obscuris, and raphe magnus [65]. 5-HTergic projections to the dorsal horn predominantly arise from the raphe magnus. Efferents form raphe pallidus and obscuris project to the ventrolateral white matter and terminate on motoneurons in the intermediate gray and ventral horns.

\subsection{Afferent projections to the raphe}

The function of 5-HTergic neurons is modulated by both long-range afferents as well as inter-raphe signaling from 5-HTergic and non-5-HTergic neurons. The rostral, but not caudal, dorsal raphe as well as the rostral part of the DRVL receive input from $\beta$-endorphin fibers originating in the arcuate nucleus of the hypothalamus. These arcuate-originating fibers form synaptic connections with GABAergic interneurons in the dorsal raphe, but not MnR, and may mediate opioid disinhibition of the 5-HTergic system. The DRVL also receives input from the lateral and perifornical hypothalamus $[50,66]$ as well as the median preoptic nucleus and the BNST $[66,67]$. The DRV primarily receives input from the lateral orbital cortex, but also receives a small number of fibers from the basomedial, anterior cortical, and anterior nuclei of the amygdala $[50,66]$. The DRD receives input from the infralimbic cortex and the BNST. The DRC receives fairly sparse afferents compared to other raphe nuclei, but inputs arise from many regions including the $\mathrm{mPFC}$, lateral habenula, interpeduncular nucleus, lateral tegmental area, substantia nigra, and several hypothalamic nuclei (i.e., lateral, perifornical, and arcuate nuclei) [50,66]. Innervation of the DRI is unknown, but correlative evidence suggests it receives afferents from the lateral part of the parabrachial nucleus [68]. The MnR receives input from the lateral habenula [69], median preoptic nucleus [67], laterodorsal tegmental nucleus, B9 5-HTergic cells [57], dorsal raphe, raphe pontis, and raphe obscuris [70,71]. Figure 2 summarizes afferent projections to each of the raphe nuclei.

\subsection{Microcircuitry of the raphe nuclei}

A variety of neurotransmitters and neuropeptides influence 5-HTergic neurons via longrange input from the forebrain and brainstem. As indicated in the previous section, afferents to the raphe show clear topography, with different 5-HTergic cell groups receiving distinct inputs. Consequently, 5-HTergic neurons display heterogeneous responses to environmental stimuli such as stress [68, 72-76]. 5-HTergic cell subpopulations, as well as non-5-HTergic cells that surround them within the raphe nuclei, exhibit disparate receptor profiles, which enables them to respond to a variety of incoming neurotransmitters and neuropeptides including: glutamate [77], corticotropin-releasing factor (CRF) [78], catecholamines [79], Substance P [80], gamma-aminobutyric acid (GABA), cholecystokinin (CCK), vasoactive intestinal peptide (VIP), somatostatin, dynorphin, neurotensin, thyroid releasing hormone (TRH), enkephalin, and neuropeptide Y [81]. The presence of somatodendritic 5-HT1A receptors has been associated with inhibitory feedback on both direct and indirect inhibition 
of 5-HT neurons (as previously mentioned). Recently, a subpopulation of 5-HT neurons lacking 5-HT1A receptors has been described, indicating the presence of subpopulations of 5-HT neurons that are controlled by separate regulatory mechanisms [82].

5-HT neurons were long considered to be a homogeneous population, but the discovery of 5HTergic cells in the raphe that do not require the expression of plasmacytoma expressed transcript 1 (Pet1), a transcription factor once thought to be necessary for 5-HT neurons differentiation, stimulated research into distinct 5-HT neuron populations [83]. Axonal morphology studies in rats revealed that dorsal raphe axons possess fine, beaded varicosities while MnR axons exhibit large round, sparse varicosities, and that these axons display disparate sensitivity to amphetamines [84]. Larger axons originating from the MnR were found to form "baskets" around the soma and proximal dendrites of neurons in the cortex and hippocampus [84]. These 5-HTergic baskets form almost exclusively around GABAergic interneurons of non-parvalbumin (PV) phenotypes, indicating that MnR regulation of cortical and hippocampal activity is mediated through direct modulation of GABAergic, but not glutamatergic, activity [85]. In addition to structural differences, 5HTergic neurons also exhibit different electrophysiological properties. For instance, it is known that subpopulations of 5-HTergic neurons possess differences in firing rate, inhibitory response to 5-HT1A/B agonists, excitability, and theta wave activity [86-91].

Besides 5-HT-producing neurons, the raphe nuclei also contain non-5-HTergic cell types including GABAergic interneurons (co-expressing somatostatin but apparently not CCK or VIP) that are typically organized along the lateral areas of the raphe nuclei [81, 92]. These GABAergic neurons function to regulate input onto 5-HT neurons. Local 5-HT release activates 5-HT receptors, including 5-HT1A, 5-HT2A/C, and 5-HT7 subtypes, generally resulting in activation of GABAergic neurons [92-95], and reduced firing frequency of 5-HT neurons in the dorsal raphe and 5-HT release of in the mPFC [95]. Activating these GABAergic interneurons may increase inhibitory postsynaptic currents in 5-HTergic neurons, thereby forming an indirect, local inhibitory feedback loop on 5-HTergic neurons [92-94], and regulate 5-HTergic firing patterns during various sleep-wake states [96]. Some 5-HTergic neurons express GAD67, an enzyme necessary for GABA synthesis, suggesting that a subset of dorsal raphe neurons co-release 5-HT and GABA [81]. Glial cells in the raphe nuclei can also regulate 5-HT neuron function. For instance, astrocytes express several 5-HT receptor subtypes, including 5-HT1A. 5-HT stimulates astrocytic release of S100 calcium-binding protein $\beta(\mathrm{S}-100 \beta)$ through activation of these 5-HT receptors, and is involved in the positive outgrowth of 5-HTergic terminals during development $[97,98]$. As discussed in the following section, astrocytic expression of S-100 $\beta$ is increased in the location and during a time of 5-HT outgrowth [98, 99].

As noted in section 2.3, the raphe nuclei receive glutamatergic input from several forebrain regions [77, 100]. Interestingly, there is also evidence for subpopulations of glutamatergic cells within the raphe system itself [80]. Some neurons in the raphe express VGLUT3, which is required for packaging of glutamate into vesicles for release. Many of these VGLUT3-positive neurons also express the Substance P receptor neurokinin 1 (NK1). Activation by Substance P leads to increased release of 5-HT locally, but reduces 5-HT release in the forebrain via 5-HT1A receptor-dependent mechanisms [80]. Another cell 
population expresses VGLUT3 and 5-HT in the same terminals, indicating the presence of neurons that may co-release 5-HT and glutamate [80]. Cells expressing Substance P can be found in the RDR, DRV, and DRI and is likely co-expressed along with 5-HT in the ventrally located DRV and DRI [79].

\section{Ontogeny of the rodent 5-HTergic system}

The placenta provides the initial source of 5-HT for the mammalian embryo [101]. Beginning around rodent embryonic day (E) 10.5, which approximates the start of the second trimester in humans [102], the neural tube closes and brainstem progenitor cells originating from ventral neuroepithelium begin to show a '5-HTergic phenotype'. By E19, these 5-HTergic neurons migrate into subgroups that resemble groupings described in the adult rodent brain [103]. As noted earlier, these neurons form two distinct cell groups: (a) a rostral group in the midbrain and rostral pons (typically defined as B9-B6, which projects to the forebrain); and (b) a caudal group (B5-B1) in the medulla oblongata and caudal pons that eventually sends descending projections to brainstem structures and spinal cord [53].

\subsection{Origins and differentiation of 5-HT neurons}

The developing mammalian brain is broadly comprised of three basic components: the forebrain, midbrain, and hindbrain. 5-HT progenitor cells reside in the embryonic hindbrain, which is subdivided along the anteroposterior axis into 12 segments (the isthmus and 11 rhombomeres) distinguished by distinct gene expression profiles [104] (Figure 3). Cells derived from specific rhombomeres eventually mature into functionally- and anatomicallydistinct 5-HTergic nuclei. For instance, while 5-HT progenitor cells are located in rhombomeres (r) 1-3 and 5-7, cells originating in r1 later form 5-HT nuclei B7, B6 and B4, while r1- and r2-derived 5-HT neurons contribute to formation of B9, B8 and B5 nuclei [105].

5-HTergic cell differentiation is driven by a cascade of signaling molecules including the morphogens fibroblast growth factor (FGF)-4, FGF8, and sonic hedgehog (SHH) [106]. FGF4 is released dorsally by the primitive streak, and is integral for specifying the establishment of 5-HT rather than dopamine (DA) neurons in the rostral hindbrain [107]. FGF8 is released from the isthmus, or midbrain-hindbrain organizing center (MHO). Rostrocaudal displacement of the MHO causes a likewise shift in the rostrocaudal expression of 5-HT neurons. Constitutive expression of the SHH receptor smoothened displaces 5-HTergic neurons into the cerebellum, indicating a role for SHH in establishing dorsoventral patterning of 5-HT neurons [108]. SHH also induces transcription factors NK2 homeobox 2 (Nkx2.2) and NK6 homeobox 6 (Nkx6.1), which cooperatively induce transcription factors Gata2 and Gata3 to drive rostral and caudal 5-HT neuron differentiation, respectively [109]. $N k x 2.2$ permits 5 -HT neuronal differentiation by inhibiting paired-like homeodomain protein $2 \mathrm{~b}$ (Phox $2 b)$, which typically blocks 5-HT neuron differentiation [110]. 5-HT neuronal differentiation also requires expression of the basic-helix-loop-helix protein, Mash1 (mouse achaete-schute homolog 1; Ascl1), which is coexpressed with $N k \times 2.2$ in the hindbrain [111] as well as other transcription factors acting 
downstream of $N k x 2.2$, including Pet1 [112] and LIM homeobox transcription factor 1-beta $(L m x 1 b)$.

\subsection{Outgrowth of 5-HTergic fibers}

There are three main phases of 5-HT fiber development: a period of axonal elongation from E13-16 followed by differentiation of specific pathways from E15-19, and finally a period of terminal field innervation and elaboration from E19-21 [103]. 5-HT innervation in rodents continues to develop through the first few weeks of life, reaching adult density of fibers around postnatal day (P)21 [113].

Multiple molecules (including 5-HT itself) influence 5-HT fiber elaboration in the developing brain. Expression of the 5-HT synthetic enzymes TPH2 (which begins around E10-10.5 [114]) and AADC (which appears at E11.5 [115]) results in the production of 5HT, which serves a trophic role in 5-HT circuit development by auto-regulating 5-HT production and axonal outgrowth of 5-HT raphe neurons. Brain derived neurotrophic factor (BDNF) also promotes 5-HT neuron development by increasing 5-HT synthesis as well as 5HT neuron survival and sprouting [116, 117]. For example, applying 5-HT or 5-HT1A receptor agonists to E14 cultured raphe neurons results in a dose-dependent increase in $B d n f$ expression and the number of neurons expressing a 5-HTergic phenotype [118]. S100 $\beta$ also plays multiple roles in promoting 5-HT neuron development, including supporting cytoskeleton stabilization, neurite extension, and axonal proliferation $[98,119]$. S100 $\beta$ is secreted by astrocytes in a 5-HT-dependent manner, since decreased 5-HT levels leads to reduced S100 $\beta$ levels $[120,121]$ while 5-HT agonists stimulate S100 $\beta$ secretion [122]. Indeed, 5-HT may indirectly regulate its own outgrowth in a positive manner through stimulating 5-HT receptors on astrocytes, resulting in the release of S100ß.

In a more direct fashion, 5-HT can inhibit its own outgrowth through activation of somatodendritic auto-inhibitory 5-HT1A receptors expressed by 5-HT neurons.

Developmental exposure to increased 5-HT levels, either through pharmacological agents (such as cocaine, monoamine oxidase inhibitors, and SSRIs) or through genetic manipulations (i.e. knocking out Sert, Maoa, or Tph2), can trigger life-long 5-HT circuit changes including reduced firing of dorsal raphe 5-HT neurons [123], reduced expression of Tph2 and Sert mRNA in raphe nuclei [42], perturbed 5-HT innervation in the limbic forebrain $[42,124,125]$, and diminished monoamine content in several forebrain regions [36, 59, 126-128]. This will be discussed in more detail below in Section 3.4.

\subsection{Roles of 5-HT in the developing brain}

Interestingly, non-5-HTergic neurons in forebrain regions (predominantly hippocampus, cortex, thalamus, and striatum) begin to transiently express SERT around E12 during early brain development $[129,130]$. This is unusual since SERT expression is typically restricted to 5-HT synthesizing neurons to permit capture of synaptic 5-HT. During early phases of brain development, neurons that transiently express SERT may do so in order to regulate 5HT signaling in target fields particularly sensitive to 5-HT levels. For instance, SERT expression can be found in the rodent hippocampus as early as E17 through P14 [130] where it is thought to help establish 5-HT innervation [101] and regulate neurogenesis, neuronal 
differentiation, neuropil formation, dendritic pruning, axon myelination, and synaptogenesis [98].

Much of what is known about 5-HT's roles as a trophic factor derive from studies examining the effects of 5-HT depletion in the perinatal rodent brain. Replacing the $T p h 2$ gene with enhanced green fluorescent protein (EGFP) interferes with 5-HT production in the developing as well as adult brain and triggers marked 5-HTergic circuit abnormalities, including hypo-innervation of the suprachiasmatic nucleus and paraventricular thalamic nuclei, and hyper-innervation of the nucleus accumbens and hippocampus [125]. Several studies depleted 5-HT in the perinatal rat brain via treatment with p-chlorophenylalanine (PCPA), which inhibits TPH2 activity to block 5-HT synthesis, or 5,7-DHT, a neurotoxin that selectivity kills 5-HT cells. This work showed that 5-HT depletion delayed forebrain neurogenesis [131], reduced the rate of forebrain growth [132], and lead to life-long deficiencies in dendritic maturation [133-135] as well as fewer adult hippocampal and cortical neurons [98]. Many of these effects were mediated by the 5-HT1A receptor [136139], although 5-HT1B receptors [140-142] and 5-HT2A receptors [117] also contribute. Moreover, many of 5-HT's trophic effects appear to be mediated through astrocytic S100 $\beta$ given its critical roles in regulating neuronal development and cytoskeleton stabilization (as noted above) [143].

\subsection{Deleterious effects of excessive synaptic 5-HT on the developing 5-HT system}

5-HT clearly plays numerous critical roles in the developing brain, although it is important to keep in mind that 5-HT levels must be tightly regulated since 5-HT depletion or excess can be harmful. Mice that genetically lack SERT display high levels of synaptic 5-HT from conception throughout life [144]. These SERT knock-out mice display altered cell density and reduced cortical layer IV thickness as adults [145], which is likely related to impaired cortical interneuron [146] and pyramidal neuron migration [147]. SERT blockade from P2P11 in mice reduces dendritic complexity of pyramidal neurons in the adult infralimbic cortex [148]. Excess 5-HT impairs or "arrests" spine development at P21, for instance, leading to reduced spine density in medial spiny neurons of striatum and pyramidal neurons of primary motor cortex [149]. Knocking out the 5-HT metabolizing enzyme monoamine oxidase A (MAOA) results in increased synaptic 5-HT levels during postnatal development, accumulation of 5-HT within terminals of non-5-HTergic neurons that can recapture synaptic 5-HT (including those emanating from substantia nigra, locus coerulus, and thalamus), and impairs cortical barrel formation in the primary somatosensory cortex [150, 151]. Similar to neurons in the hippocampus, thalamocortical afferents transiently express SERT during postnatal development. SERT blockade via perinatal SSRI exposure in rodents disrupts cortical barrel formation in the somatosensory cortex, which, in turn, perturbs offspring's later sensory perception $[152,153]$.

Pharmacologically enhanced levels of synaptic 5-HT during brain development (through early-life exposure to SSRIs) also cause life-long changes in rodent 5-HT circuits. For example, postnatal exposure to the SSRI citalopram leads to lasting reductions in SERT+ fibers in both dorsal and ventral hippocampus [124]. Early-life citalopram exposure also reduces TPH 2 expression throughout the rostrocaudal extent of the dorsal raphe and the 
MnR [42]. Neonatal exposure to the tricyclic antidepressant clomipramine reduced 5-HT levels in the hypothalamus, frontal cortex, brainstem, and hippocampus [126-128]; it also reduced firing rate and altered temporal discharge of 5-HTergic neurons in the dorsal raphe [123]. The hippocampus appears to be especially sensitive to fluctuating 5-HT levels in the developing brain, with 5-HT depletion leading to 5-HTergic hyper-innervation [125] while excessive synaptic 5-HT during the perinatal period results in 5-HTergic hypo-innervation of the hippocampus [124].

\section{Perinatal SSRI exposure in humans - clinical findings}

An estimated 10-20\% of women experience depression or anxiety during pregnancy, and 2$13 \%$ of women take an SSRI during pregnancy [154-156]. With an estimated 4 million newborns each year, this equates to approximately 80,000-520,000 newborns exposed to an SSRI in utero. Although SSRIs are generally considered safe, with minimal risk for major pregnancy complications or fetal malformation [157], there is limited knowledge of the long-term consequences of perinatal SSRI exposure on human brain maturation and behavior. Most studies to-date have described either 1) an abstinence syndrome that can occur in newborn babies exposed to SSRIs in utero; or 2) abnormal cognitive and social behaviors reported in some young children that were exposed to SSRIs in early life. These findings are summarized below.

\subsection{Neonatal outcomes following in utero SSRI exposure}

In 2005, the FDA issued a warning against using the SSRI paroxetine during pregnancy due to reports of fetal cardiovascular malformation [158-160]. Similar concerns were raised for other SSRIs, including fluoxetine [160-162], citalopram [162, 163] and sertraline [162165]; subsequent studies concluded that the effects were small and that SSRIs generally pose minimal teratogenic risks [161, 163-172]. Apart from this, reduced birth weight and gestational length have been associated with prenatal SSRI exposure when compared to infants born to depressed mothers that did not receive treatment [173-175].

Neonatal abstinence syndrome (NAS), which includes poor neonatal adaption and neonatal withdrawal, is the most commonly reported adverse neonatal outcome associated with earlylife SSRI exposure as it occurs in approximately $30 \%$ of exposed infants [176-182]. This transient syndrome is comprised of a range symptoms resulting from cessation of long-term in utero SSRI exposure. Clinicians group symptoms into 4 categories including: 1) gastrointestinal (poor feeding, vomiting, uncoordinated sucking); 2) autonomic (sweating, fever); 3) respiratory (tachypnea); and 4) central nervous system disruptions (restlessness, tremors, sleep troubles, hyper- or hypotonicity) [182]. Severity of NAS symptoms peaks 2-4 days after birth in SSRI-exposed newborns, and afterward the likelihood of developing NAS symptomology decreases [180, 181]. Symptoms then dissipate within a few weeks after birth.

It is unknown why some SSRI-exposed infants develop NAS while others are resistant. One study examined polymorphisms of SLC6A4, the gene that encodes SERT in humans. Polymorphisms in the $S L C 6 A 4$ promoter influence gene transcription and ultimately SERT function. A 44 base pair insertion/deletion polymorphism in the 5' regulatory region of 
SLC6A4 is responsible for several variants, most notably the short $(s)$ and long $(I)$ allelles $[183,184]$. Because the $s$ allele is associated with reduced SERT transcription and 50\% reduction in 5-HT reuptake, these children may be primed for poor outcomes following prenatal SSRI exposure. Evidence for long-lasting behavioral disturbances (discussed in the following section) is closely tied to the presence of poor neonatal adaptation or NAS [29].

Findings from a handful of studies indicate that early life SSRI exposure can affect a child's stress and pain reactivity. At two months of age, infants exposed to SSRIs in utero exhibit blunted responses to a painful stimulus [180, 185]. At three months, SSRI-exposed infants displayed increased serum cortisol binding globulin and reduced salivary cortisol, which contribute to blunted diurnal cortisol variation $[186,187]$. Together these studies suggest that early life SSRI exposure disrupts neural circuits that regulate somatosensory function, nociception, and the hypothalamic pituitary adrenal (HPA) stress axis.

\subsection{Effects of perinatal SSRI exposure on infant and childhood behavior}

A limited number of studies have examined possible cognitive, social, and emotional behavioral alterations in children with a history of early life SSRI exposure. At 10 months of age, early life SSRI exposure was associated with low social-emotional and adaptive behavior test scores on the Bayley Scales of Infant Development (third edition) [154]. These early differences in social and emotional behavior persist since children aged three to six years old with a history of early life SSRI exposure were found to display abnormal social behavior [29], increased internalizing behavior (e.g., anxiety) [28, 33, 155, 188], but no association with attention-deficit/hyperactivity disorder [34, 189]. (Notably, one study failed to find an association between early life SSRIs and risk for internalizing behaviors [190].) Not all studies have associated early life SSRI exposure with detrimental outcomes, as some found increased readiness to interact at 3 months of age and increased speech perception through 10 months of age [191, 192]. Early life SSRI exposure alone does not appear to impact childhood IQ [33, 193-195]. Although one study found reduced IQ in SSRI-exposed children, the comparison group was children of non-depressed mothers, suggesting that prenatal maternal mood has a more pronounced impact on childhood IQ than SSRI exposure [196]. Interestingly, though, these effects may depend on SLC6A4 polymorphisms since SSRI-exposed children with at least one short $S L C 6 A 4$ allele were more resilient to poor maternal mood (displayed better executive function) compared to those with the long allele [197].

Studies in recent years have begun to examine the possibility that early life SSRI exposure increases children's risk for developing neurodevelopmental disorders such as autism [198, 199]. More than $25 \%$ of children affected by autism spectrum disorder (ASD) exhibit elevated whole blood 5-HT levels [200]. This finding coupled with 5-HT's numerous roles in shaping neurodevelopmental processes, somatosensory systems, and social behavior (all domains relevant to symptoms of ASD) support the notion that altered 5-HT signaling plays a role in the pathogenesis of ASD [201]. A case-controlled study by Croen et al. first reported increased risk for ASD in children exposed to SSRIs during the first trimester of pregnancy [30]. Since then, five out of eight studies, most of which consisted of large, population based cohorts, found a significant association between prenatal SSRI exposure 
and increased risk for ASD. Exposure during the first trimester was more commonly associated with increased risk for ASD [30, 202]; however, one study found an association with second and third trimester exposure [201], and another reported a stronger link between ASD risk and total amount of time exposed to an SSRI in utero [203].

The studies summarized here point to a number of physiological and behavioral abnormalities occurring in children exposed to SSRIs in early life. Until recently, none of the work in humans to-date examined effects beyond childhood, so the long-term consequences of early-life SSRI exposure on human behavior remain unknown. However, one study has now found increased prevalence of depression, but not ADHD, in adolescents exposed to SSRIs in utero [34]. Several rodent studies show that perinatal SSRI exposure causes lifelong adverse outcomes, including increases in anxiety- and depression-like behavior (broad overview in Figure 4; detailed in the next section). Consequently, there is urgent need to follow children exposed to SSRIs in utero as they age to determine whether they, too, exhibit heightened risk for developing mood disorders in adulthood.

\section{Impact of perinatal SSRI exposure on rodent behavior}

Early life exposure to SSRI antidepressants elicits a variety of long-term neurobehavioral adaptions in mice and rats. These behavioral abnormalities span a number of domains relevant to human psychopathologies, including perturbations of social behavior, cognition, behavioral inhibition (i.e., anxiety-like behavior), and behavioral despair. These findings are summarized in Table 2 and in the paragraphs below.

\subsection{Social behavior}

Early life SSRI-induced changes in rodent social behavior are of particular interest in relation to ASD since a key component of ASD symptomatology is a lack of social interest or engagement [156], although perturbed social behavior would certainly be relevant to mood disorders such as major depression or anxiety disorders as well. Perinatal SSRI exposure has been shown to reduce social play behavior in juvenile or adolescent rats [44, 204-207]. In adult offspring, perinatal SSRI exposure has disparate effects on males versus females, leading to reduced sexual activity in males that were exposed to perinatal SSRIs [42, 204, 208-212], but increased sexual responsiveness in perinatal SSRI-exposed females [209]. Two independent studies found reduced aggression in perinatal SSRI-exposed adult males [213, 214].

\subsection{Cognitive performance}

Early life SSRI exposure has been shown to improve rodents' cognitive performance. Prenatal exposure to the SSRI fluoxetine reduced juvenile Wistar rats' latency to find the hidden platform in the Morris Water Maze (MWM; an indication of improved memory) [215]; however, fluoxetine exposure did not affect MWM performance in female mice [216]. Similarly, early postnatal exposure to the SSRI citalopram increased adult Long-Evans rats' exploration of a novel object in the novel object recognition task (another indicator of improved cognitive ability) [204]. These findings appear to corroborate clinical findings 
suggesting that early life SSRI exposure has no detrimental effect on children's cognitive performance.

\subsection{Behavioral inhibition (anxiety and exploratory behavior)}

Many studies suggest that perinatal SSRI exposure leads to lifelong increases in rodent anxiety-like behavior, although these findings are mixed, with some studies reporting no effects (Table 2). The majority of these studies used classic tests of rodent anxiety such as the Elevated Plus Maze (EPM) and Open Field (OF) test, which assess rodents' internal conflict between voluntary approach and withdrawal tendencies in novel, potentially threatening environments [217]. In general, animals that are more anxious spend less time exploring potentially threatening regions of a test apparatus (i.e., open arms of the EPM or central region of the OF), instead preferring relatively safer areas of the apparatus (i.e. dark, enclosed arms of the EPM or periphery/corners of the OF). A handful of studies used the novelty-suppressed feeding task (NSF; also known as the novelty-induced hypophagia test), another anxiety-related task where a 12-24 hour food-deprived rodent is placed in a novel environment with food available to test how long the animal takes to venture into the new environment to obtain the food [218].

In the OF test, slightly more than one half of the studies reported reduced exploratory behavior in perinatal SSRI-exposed adult rodent offspring [40, 42, 148, 206, 213, 215, 219, 220]; one study found increased exploratory behavior [42] and the rest found no effect of SSRI exposure on OFT behaviors [39, 216, 221-225]. In the EPM, most studies found that early life SSRI-exposed offspring displayed reduced exploration in the open arms [40, 205, $216,226]$, although several more reported no effect [208, 215, 219, 221, 223, 225], and one found increased open arm exploration [213]. Two studies utilized the NSF task, with both reporting that perinatal exposure to the SSRI fluoxetine increased anxiety-like behavior (latency to feed) [148, 205]. Overall, approximately half the studies reviewed here found that perinatal SSRI exposure increased anxiety-like behavior in adult offspring, while the other studies found no effect.

\subsection{Behavioral despair (forced swim test immobility)}

Many reports examined the effects of perinatal SSRI exposure on adult depression-like behavior, which is typically assessed using the forced swim test (FST). The FST was initially described by Porsolt nearly 40 years ago [227] and has remained a mainstay as a test of rodent behavioral despair. In the FST, a rat or mouse is forced to swim in an inescapable cylinder of water. After an initial period of vigorous activity (swimming or climbing in attempt to escape the water), an animal eventually becomes immobile, only making movements necessary to keep its head above water. The amount of time spent immobile in the FST is interpreted as an animal's level of despair or helplessness, whereby the rat or mouse gives up in struggling since escape is impossible. One of the most important features of the FST is the fact that it is sensitive to a wide range of antidepressant drugs. Several drugs that are clinically effective in treating depression (i.e. SSRIs, tricyclic antidepressants, monoamine oxidase inhibitors) effectively reduce FST immobility in adult rodents [228, 229]. We found 19 publications that evaluated FST behavior in adult rodent offspring that were exposed to SSRIs during early life. The majority of these studies found 
that perinatal SSRI exposure increased adult FST immobility [36, 38, 39, 148, 206, 213, 223, 225, 226, 230-233]; three studies found no effect of perinatal SSRI exposure [224, 234, 235], and three reported decreased FST immobility [216, 220, 236] (Table 2).

One quarter of the studies reviewed here examined the effects of perinatal SSRI exposure on mice. Early life fluoxetine exposure lead to increased adult FST immobility in 129S6/ SvEvTac mice [148] and Swiss mice [213]. Perinatal SSRI exposure had no effect on FST immobility of CD1 mice [234], and lead to decreased FST immobility in C57BL/6J mice [216, 220]. Similarly, mice genetically lacking SERT (5htt-/- on a 129S background) also exhibited increased FST immobility [237]. These data suggest that certain inbred mouse strains (i.e., C57BL/6J, CD1) may be resistant to the adverse effects of perinatal SSRI exposure while others (such as mice on a 129S or Swiss background) are susceptible. It may be that certain mouse strains (such as $129 \mathrm{~S} 1 / \mathrm{SvlmJ}$ mice) are generally more susceptible to early-life manipulations compared to C57BL/6J mice since other work showed that 129S1/ Svlm mice were more vulnerable than C57BL/6J to early life maternal separation, leading to increased adult FST immobility [238].

The majority of rodent studies examining lasting behavioral effects of perinatal SSRI exposure utilized either Wistar or Sprague-Dawley rat strains. Most studies using Wistars found that early life SSRI exposure increased adult FST immobility while only half of the studies using Sprague-Dawley rats found increased immobility in perinatal SSRI-exposed offspring. The discrepant findings in Wistar rats likely relates to the timing of early life SSRI exposure and behavioral assessment. The studies reporting increased FST immobility exposed Wistar rat pups perinatally or postnatally and were submitted to the FST in adulthood [36, 38, 39, 226, 230-233, 236]. The studies that found no effect of early life SSRI exposure on Wistar FST performance used a different drug treatment (treating only prenatally until P0) and performed the FST in adolescent offspring [205, 235]. These findings point to the existence of a critical period in SSRI sensitivity where the risk for adverse consequences of early life SSRI exposure (enhanced depression-like behavior) is greater when individuals are exposed during early postnatal life as opposed to the prenatal period [156].

\subsection{Technical factors that may contribute to discrepant behavioral effects of perinatal SSRI exposure}

Discrepant findings among the studies noted above likely stem from a number of technical factors including using different (a) SSRI antidepressants; (b) route of drug administration (i.e., treating pregnant/lactating mothers versus directly injecting pups); (c) species (mouse/ rat) or strain used; (d) timing of drug administration during pregnancy or the early postnatal period; and (e) the spectrum of behavioral assays and test conditions used to assess offspring behavior. Furthermore, another important factor to consider in these studies is the age at which perinatal SSRI-exposed offspring undergo behavioral testing, since the adverse effects of SSRI exposure may not emerge until adulthood [205]. Indeed, one of the studies noted above using Wistar rats [235] and one of the studies using Sprague-Dawley rats [224] that failed to see effects of early life SSRI exposure on FST immobility conducted the testing in adolescents. The studies reporting perinatal SSRI-induced increases in behavioral despair 
conducted FST testing in adult offspring (Table 2). Together, these findings suggest that perinatal SSRI exposure increases behavioral despair in adult, but not adolescent rats. This would be consistent with a prior study showing that early life exposure to the SSRI fluoxetine elicited greater anxiety-like behavior specifically in adult mice with no detectable effects in preadolescent offspring [45, 205].

\subsection{Individual differences in susceptibility to adverse behavioral effects of early life SSRI exposure in rodents}

Apart from technical issues discussed above that influence the behavioral outcomes in rodents exposed to SSRIs during early life, another moderating factor pertains to naturallyoccurring emotionality differences among experimental animals that may convey distinct susceptibility (or resistance) to perinatal antidepressant exposure. The phenomenon of individual differences in emotional behavior is well-known [239-246]. Many behavioral traits exist in a spectrum, with some individuals expressing high, medium, or low levels of a given characteristic. Moreover, certain behavioral traits can predict a constellation of other behavioral attributes. For instance, individual differences in novelty reactivity predict several other behaviors, including response to psychostimulants [240], HPA stress axis reactivity [247-249], and anxiety- and depression-like behavior [239, 250-256] (for review see [246]).

Our research group recently showed that Sprague-Dawley rats that were selectively bred for high versus low novelty seeking traits exhibit differential susceptibility to perinatal exposure to the SSRI paroxetine, with low novelty responding (LR) rats displaying increased FST immobility in response to early life SSRI exposure while high novelty responder (HR) rats were unaffected [223]. Thus, in previous perinatal SSRI exposure studies in rats and mice, experimental groups may have included a mix of animals with more high novelty responding (HR)-like or low novelty-reactive (LR)-like tendencies. Experimental groups that were inadvertently skewed in favor of perinatal antidepressant-resistant/HR-like rats might have found limited behavioral abnormalities in response to neonatal antidepressant exposure, while cohorts that included more perinatal antidepressant susceptible/LR-like rats might have found strong effects. Our findings may also indicate possible reasons why human individuals respond differently to perinatal antidepressant exposure. For example, Klinger et al. 2011 reported increased social behavior abnormalities in children ages four to six who were exposed to SSRIs during gestation and showed signs of antidepressant withdrawal at birth; however, SSRI-exposed children that showed no signs of antidepressant withdrawal as infants exhibited normal social behavior at ages four to six. Similarly, there are conflicting reports of the association between perinatal SSRI exposure and risk of autism [30-32, 257]. Together these studies indicate that both humans and experimental animals exhibit individual differences in susceptibility to the effects of early-life antidepressant exposure.

\section{Neural mechanisms potentially underlying perinatal SSRI-induced behavioral abnormalities: focus on the hippocampus}

Although neonatal antidepressant exposure is known to disrupt rodent 5-HT circuit development (e.g., changes in the dorsal raphe or 5-HTergic innervation of limbic targets as described in Section 3.4), surprisingly little is known about neonatal SSRI-induced 
molecular abnormalities beyond the 5-HT system that may contribute to trigger its adverse effects on emotional behavior. Neonatal citalopram exposure lead to increased firing of noradrenergic neurons in the locus coeruleus [258], increased noradrenergic fiber density in the neocortex [259], and perturbed axon myelination in the corpus callosum [44]. Postnatal fluoxetine exposure induces long-term up-regulation of histone deacetylase 4 (Hdac4) mRNA in the hippocampus of adult drug-exposed offspring [206], and another found minimal hippocampal and amygdalar gene expression changes in adult offspring that were exposed to escitalopram in early life [260].

The work noted above focused on neurobiological changes in the adult brain following perinatal antidepressant exposure with no studies examining SSRI-induced alterations in developing brains during the period of drug exposure. This knowledge gap motivated a recent transcriptome study in our laboratory where we examined widespread gene expression changes in the developing (P7, P14, P21) and adult (P75) hippocampus and amygdala of offspring that were perinatally exposed to the SSRI paroxetine [223]. This microarray experiment revealed robust perinatal SSRI-induced gene expression changes in the early postnatal limbic brain, particularly within the hippocampus. Early life paroxetine exposure affected a number of transcripts in the developing and adult hippocampus, including genes involved in neurogenesis, synaptic plasticity, and epigenetic processes. The following section touches on each of these topics, highlighting potential roles for each in contributing to behavioral abnormalities triggered by early life SSRI exposure.

\subsection{Role of the hippocampus in mediating cognition, anxiety, sociability, and behavioral despair}

The hippocampus is critical to learning and memory processes [261-265], regulation of the HPA axis [266, 267], processing emotionally salient information from the environment [268-270], and controlling emotional behavior [266, 267, 271-275]. In rats and mice, the hippocampus (HPC) can be functionally subdivided into dorsal (dHPC) and ventral (vHPC) regions, which each have distinct afferent and efferent connections [276]. The dHPC is reciprocally connected to the anterior cingulate and retrosplenial cortices as well as the mammillary nuclei $[277,278]$. The vHPC, on the other hand, is functionally connected to the mPFC [279, 280], hypothalamus [281], nucleus accumbens [282], amygdala (AMY) and the BNST [281-283]. Based on the networks these hippocampal subregions are integrated with, it has been suggested that the dHPC primarily contributes to learning and memory processes while the vHPC plays a significant role in emotional processing [284-286].

The hippocampus plays an important role in regulating fear and anxiety-like behavior [271274, 285-290], in part via its abundant neural connections with limbic structures that convey emotionally-salient information from the environment. It has been suggested to be at the center of a neural 'behavioral inhibition system', which is activated during anxietyprovoking or conflict situations to guide appropriate behavioral response to threat. Accordingly, it has been postulated that excessive levels of anxiety-like behavior may derive from an over-activation of this behavioral inhibition circuit [273].

A number of studies indicate a role for the hippocampus in regulating social behaviors. Hippocampal lesions can lead to reduced aggression [291, 292], diminished social 
investigation [293, 294], and impaired male sexual behavior [295]. The CA2 region of the hippocampus has been found to be critical for social memory, although does not appear to mediate sociability per se $[296,297]$. Recent optogenetic studies demonstrated that the ventral hippocampus influences social behavior specifically via projections from the basolateral amygdala [298]. Other work using designer receptors exclusively activated by designer drugs (DREADDs) revealed a role for parvalbumin-positive interneurons in the dentate gyrus also playing a role in regulating social interaction [299].

The hippocampus likely plays an important role in mediating behavior in the FST given its capacity to regulate the stress, behavioral despair, and learning/memory components involved in the task [300]. Inhibiting vHPC-mPFC network activity with localized injection of lidocaine to either region blocks the long-term antidepressant-like effects of ketamine in the FST. Interestingly, optogenetic activation of this pathway was not sufficient to mimic the effects of ketamine on FST immobility on its own, but required dorsal raphe inactivation (via bicuculline injection) to reduce FST immobility [301].

The following sections review how 5-HTergic tone, neurogenesis, and epigenetic mechanisms impact hippocampal function and how perinatal SSRI exposure may modulate these processes to trigger behavioral dysfunction in adulthood.

\subsection{Hippocampal 5-HT signaling and how it is affected by perinatal SSRI exposure}

The hippocampal formation receives well defined patterns of 5-HTergic innervation from various raphe cell groups, including the DRC, DRI, and MnR [50]. 5-HT impacts hippocampal function in myriad ways given that essentially every 5-HT receptor subtype can be found expressed in the hippocampus within its multiple cell types - pyramidal neurons, GABAergic interneurons, or astrocytes [302-308]. For instance, through activation of the 5HT1A receptor [309], 5-HT modulates gamma oscillations, an important synchronization mechanism thought to influence behavior by linking activity of distributed cells in the hippocampus [310, 311]. 5-HT1 receptors are densely expressed in the hippocampus; presynaptic 5-HT1B/D receptors critically regulate 5-HT release in the hippocampus, while post-synaptic 5-HT1A receptors located on pyramidal and granular neurons [302] as well as glial cells [312] regulate a number of functions, including neurogenesis in dentate gyrus [313]. 5-HT1B receptors are expressed at relatively low levels [314] and appear to mediate presynaptic inhibition of local synapses between CA1 pyramidal cells and interneurons [315]. 5-HT3 receptors, ionotropic receptors primarily located in interneurons in the rat hippocampus [304] are thought to modulate LTP [316]. 5-HT4 receptors appear to act through regulating cholinergic transmission [317], although other work shows that 5-HT4 receptors also work together with 5-HT5 and 5-HT7 receptors to regulate BDNF levels in hippocampus [318]. Finally, 5-HT7 receptors have been shown to increase excitatory input onto GABAergic interneurons [319], increase GABA release [319, 320], and inhibit AMPA receptor-mediated current in Schaeffer collateral synapses between CA3-CA1 [321].

As noted in section 3.3, the hippocampal formation is one of a few brain regions that transiently expresses SERT during early postnatal life. In the developing rat brain, SERT is expressed by hippocampal neurons from E17-P14 [130], indicating the importance of regulating 5-HT transmission in the hippocampus during this critical period in hippocampal 
development. SSRI exposure during this time frame leads to decreased TPH2 expression throughout the rostro-caudal extent of the midline cell groups innervating the hippocampus and a corresponding reduction in 5-HTergic fibers in the dHPC and vHPC from P21 through adulthood $[42,124,226]$. Similarly, perinatal exposure to the tricyclic antidepressant clomipramine resulted in increased 5-HT1a mRNA expression in the adult hippocampus [233], and decreased presynaptic 5-HT1a expression in the dorsal raphe [226], likely a compensatory mechanism for lower 5-HT production. Interestingly, a separate body of work showed that reducing 5-HTergic tone via acute dietary tryptophan depletion is not enough to alter FST immobility or spatial memory in adult Sprague-Dawley rats [322]. When compared to studies that show inhibition of 5-HT synthesis via parachlorophenylalanine during gestation increases despair behavior and impairs MWM performance in the adult animal [323], these findings suggest that timing of acute reductions in 5-HT content may be necessary for changes in behavior. The behavioral effects of perinatal SSRI exposure may be reversible, as one study showed that SSRI treatment in adulthood was able restore rodent behavior [230].

\subsection{Effects of perinatal SSRI exposure on neurogenesis}

Neurogenesis in the developing hippocampus occurs in late gestation (E16-20) in the Cornu Ammonis (CA) regions and first two postnatal weeks (P0-19) in the dentate gyrus [324]. Although this initial phase of neurogenesis in the dentate gyrus tapers around weaning at P21, it persists at low levels through adolescence and adulthood [325]. As noted above in Section 6.2, the activation or inhibition of specific 5-HT receptors can influence hippocampal adult neurogenesis in a variety of ways [326]. For example, activation of 5HT1A and 5-HT2B receptors increases neurogenesis, activation of 5-HT1B and 5-HT2C receptors has no effect neurogenesis, but blocking 5-HT1A and 5-HT1C decreases proliferation. While antidepressant treatment has been shown to increase adult neurogenesis, it is controversial whether increasing neurogenesis alone is sufficient to improve depressionlike behavior (i.e. immobility in the FST) [327-330].

Much less is known about how perinatal SSRI exposure (or 5-HT perturbations in general) affect hippocampal neurogenesis in adult offspring. Our recent transcriptome study in the brains of early postnatal and adult rats that were exposed to perinatal paroxetine revealed altered expression of several neurogenesis-related transcripts. During early postnatal development, these transcripts appear to be downregulated in the hippocampus, but by P21 and through adulthood, these same neurogenic transcripts are upregulated [223]. Whether these expression changes directly reflect neurogenic activity was not determined; however, our results suggest that perinatal SSRI exposure disrupts neurogenesis in early postnatal development as well as adulthood, which may interfere with hippocampal function and behaviors sensitive to hippocampal function (i.e. behavioral inhibition and behavioral despair). Neonatal SSRI exposure has been shown to increase hippocampal BDNF expression [220] and neurogenesis in prenatally stressed offspring [224]; however, both studies also reported reduced despair in the adult offspring so how these molecular findings relate to the majority of the rodent literature is unclear. More recently, postnatal fluoxetine has been shown to decrease hippocampal BDNF expression and increase despair in the FST [225]. 


\subsection{Effects of SSRI exposure on epigenetic mechanisms in the hippocampus}

Early-life experience profoundly affects neurodevelopment, emotional behavior, and stress reactivity, in part, through epigenetic processes [331-333]. Like stress and other environmental factors, psychotropic medications (including antidepressants, mood stabilizers and antipsychotics) can modify epigenetic processes like DNA methylation and histone deacetylation [334, 335]. Studies in adult animals show that SSRI treatment decreases cortical Dnmt1 and Dnmt3a mRNA expression [336] and decreases DNMT enzymatic activity [337], although it induces methyl binding protein expression (MeCP2 and MBD1) within multiple brain regions, including the dentate gyrus subregion of the hippocampus [338]. In addition, treating rats with a DNMT inhibitor either systemically or via intra-hippocampal infusions has antidepressant effects in the FST [339]. SSRI treatment has also been shown to reduce histone deacetylase (HDAC)-5 mRNA expression and acetylated histone $\mathrm{H} 3$ levels in multiple brain regions [340, 341], and, likewise, administering HDAC inhibitors has antidepressant effects [342-344]. Together, these findings suggest that the effects of antidepressant drugs are at least partially mediated by epigenetic changes in the hippocampus as well as other brain regions, including a downregulation of molecules involved in both DNA methylation and histone deacetylation [335]. Importantly, while antidepressant-induced epigenetic changes may be beneficial in the adult brain (thereby contributing to therapeutic actions of these medications), such alterations the developing brain may have adverse consequences.

There is limited information regarding epigenetic changes triggered by perinatal SSRI exposure. Analysis of umbilical cord blood of SSRI exposed neonates found decreased sitespecific DNA methylation, including in the promoter region of DNMT3a [345]. Perinatal SSRI exposure leads to robust gene expression changes in the developing and adult limbic brain, particularly the hippocampus, and such effects are potentially mediated through epigenetic mechanisms [206, 223]. Early life exposure to fluoxetine (from P2-P21) lead to increased hippocampal expression of histone deacetylase 4 (Hdac4) from P21 through 18 months of age as well as increased $\mathrm{H} 3$ and $\mathrm{H} 4$ acetylation at the $\mathrm{Hdac} 4$ promoter. Further, virally-mediated overexpression of Hdac4 reversed the behavioral effects of perinatal fluoxetine exposure in the FST [206]. These effects are not limited to histone acetylation, however, as postnatal fluoxetine exposure has been shown to increase histone 3 lysine 27 trimethylation at the level of the BDNF IV promoter, leading to a negative correlation between BDNF expression and immobility in the FST [225]. Another study showed that perinatal fluoxetine exposure led to decreased global DNA methylation in the hippocampus on P22 [221]. Similarly, recent work in our laboratory showed that early life exposure to the SSRI paroxetine markedly downregulated expression of DNA methylation-related molecules (DNMT3a and Mecp2) and global DNA methylation in the hippocampus, but not amygdala, septum, or mPFC, during the second week of life [346].

\section{Conclusions \& future directions for the field}

5-HT serves diverse roles in the developing and adult brain, so altering 5-HT levels during critical developmental periods can powerfully shape brain development, behavior, and lifelong emotional health [106, 347, 348]. Given the prevalent use of SSRI antidepressant 
medications among women of child-bearing age, pregnant, or nursing, there is a clear need to better understand the consequences of SSRI exposure for their children as this is one of the chief environmental factors regulating 5-HT levels in the developing brain [348]. The therapeutic benefits of SSRIs are thought to include long-lasting changes to cellular physiology, via changes in 5-HT signaling, adult neurogenesis, and epigenomic reprogramming. While these SSRI-induced adaptions are necessary for proper management of maternal depression, in utero SSRI exposure may have long-lasting maladaptive effects on the offspring. As detailed above, perinatal SSRI exposure in humans has been shown to alter neonatal behaviors, HPA function in infants and toddlers, and increase the prevalence of internalizing and abnormal social behaviors in children. Unfortunately, the effects of perinatal SSRI exposure on adolescent and adult emotional health are unknown, so an obvious critical next step for the field will be to continue to follow exposed individuals to determine whether they display long-term adverse effects akin to what has been described in rodents.

As noted earlier in this review, studies in both humans and animals show that certain individuals are more vulnerable to early-life SSRI exposure than others, but the mechanisms driving this differential susceptibility are completely unknown [348]. Identifying the molecular mechanisms that confer susceptibility should be a primary focus of future studies as these findings could not only lead to greater understanding of susceptibility to SSRI exposure, and thus individualized treatment strategies for depression during pregnancy, but also may elucidate mechanisms in the etiology of depression, particularly in those individuals that may be more susceptible to early-life environmental stressors. Furthermore, in addition to examining individual differences in susceptibility to perinatal SSRI exposure, another critical next step will be to more fully explore possible sex differences. The majority of rodent studies to-date have focused exclusively on the effects of perinatal SSRI exposure on male offspring. It will be important to determine not only whether there are sex differences in overall risk for adverse consequences of perinatal SSRI exposure, but also whether early-life SSRI exposure poses distinct risks depending on sex (for instance, possibly increasing risk for autism/social behavior abnormalities specifically in male offspring whereas increasing risk for depression/anxiety-like symptoms specifically and/or more dramatically in female offspring).

There is a growing body of evidence suggesting an approximate two-fold increased risk for ASD in SSRI-exposed children [30, 201-203]. These findings are supported by rodent studies showing that perinatal SSRI exposure leads to social impairments [44, 204-207] as well as impaired somatosensory cortex development [152, 153]. As noted earlier, SSRIs trigger a number of molecular changes in the brain, including modifications of epigenetic processes like DNA methylation [336-338], and early life SSRI exposure was found to markedly suppress expression of multiple DNA methylation-related molecules in the early postnatal hippocampus [346]. MeCP2 is a key molecule involved in DNA methylation, and mutations of the gene encoding MeCP2 has been linked to Rett Syndrome, which shares many symptoms of ASD, including stereotypic movements and low sociability. It is tempting to speculate that perinatal SSRI-induce suppression of MeCP2 expression in the developing brain contributes to later social deficits. Future studies attempting to link ASD risk with SSRI exposure should attempt to characterize expression of MeCP2 in SSRI- 
exposed children with ASD. Moreover, future rodent studies could examine the role of altered DNA methylation in mediating the adverse behavioral effects of perinatal SSRI exposure.

Given the role of DNA methylation in genomic imprinting whereby DNA methylation restricts expression of a gene to one allele, the field should consider the impact of SSRI exposure on altering the status of maternally or paternally imprinted genes. For certain genes, imprinting of one allele or the other is critical for neurodevelopmental processes [349]. While there have been no studies to-date investigating the impact of SSRI exposure on imprinted genes, unpublished data from our research group indicates that perinatal SSRI exposure induces differential methylation across the genome in the postnatal hippocampus. Using next-generation sequencing to map genome-wide methylation patterns in control and SSRI-exposed hippocampal DNA, we found differentially methylated regions in or near the gene body of three genes known or predicted to be imprinted by the Luedi model [350], including Bai3, Cacna2d1, and Gnas (Glover et al., Unpublished data). Whether such changes in methylation reflect altered imprinting of these genes has yet to be determined, but future studies may offer insight into the relative contribution of allelic imprinting of these genes in normal hippocampal development and in the SSRI-exposed individual.

In conclusion, perinatal SSRI exposure leads to changes in affective behavior including reduced sociability and increased anxiety and depression-like behaviors. Animal studies indicate SSRI exposure impairs normal brain development, with long lasting changes observed in 5-HTergic tone, neurogenesis, and epigenetic programming. Notably, emerging evidence suggests there is variability amongst individuals exposed to SSRIs during critical periods in neurodevelopment, indicating certain children may be at greater risk for developing mood disorders later in life. Future studies should focus on the impact of SSRI exposure on males versus females. As women are $70 \%$ more likely to be diagnosed with depression in general, does SSRI exposure further exacerbate this sexual dimorphism? Along the same lines, identifying why certain individuals are more likely to show adverse behavioral effects following SSRI exposure could lead to individualized treatment strategies for depressed women who are or plan to become pregnant.

\section{References}

1. American Psychiatric Association., American Psychiatric Publishing., and American Psychiatric Association. DSM-5 Task Force. Diagnostic and statistical manual of mental disorders : DSM-5 (5th). ed. 1 online resource.

2. Yonkers KA, et al. The management of depression during pregnancy: a report from the American Psychiatric Association and the American College of Obstetricians and Gynecologists. Obstetrics and gynecology. 2009; 114(3):703-713. [PubMed: 19701065]

3. Dayan J, et al. Role of anxiety and depression in the onset of spontaneous preterm labor. American journal of epidemiology. 2002; 155(4):293-301. [PubMed: 11836191]

4. Borri $\mathrm{C}$, et al. Axis I psychopathology and functional impairment at the third month of pregnancy: Results from the Perinatal Depression-Research and Screening Unit (PND-ReScU) study. The Journal of clinical psychiatry. 2008; 69(10):1617-1624. [PubMed: 19192445]

5. Marcus SM. Depression during pregnancy: rates, risks and consequences--Motherisk Update 2008. The Canadian journal of clinical pharmacology $=$ Journal canadien de pharmacologie clinique 2009; 16(1):e15-e22. [PubMed: 19164843] 
6. Bennett HA, et al. Prevalence of depression during pregnancy: systematic review. Obstetrics and gynecology. 2004; 103(4):698-709. [PubMed: 15051562]

7. Bunney WE Jr, Davis JM. Norepinephrine in depressive reactions. A review. Arch Gen Psychiatry. 1965; 13(6):483-494. [PubMed: 5320621]

8. Schildkraut JJ. The catecholamine hypothesis of affective disorders: a review of supporting evidence. Am J Psychiatry. 1965; 122(5):509-522. [PubMed: 5319766]

9. Coppen AJ. Depressed states and indolealkylamines. Adv Pharmacol. 1968; 6(Pt B):283-291. [PubMed: 5301640]

10. Hirschfeld RM. History and evolution of the monoamine hypothesis of depression. J Clin Psychiatry. 2000; 61(Suppl 6):4-6. [PubMed: 10775017]

11. Lapin IP, Oxenkrug GF. Intensification of the central serotoninergic processes as a possible determinant of the thymoleptic effect. Lancet. 1969; 1(7586):132-136. [PubMed: 4178247]

12. Leonard BE. Evidence for a biochemical lesion in depression. J Clin Psychiatry. 2000; 61(Suppl 6):12-17. [PubMed: 10775019]

13. Mann JJ. Role of the serotonergic system in the pathogenesis of major depression and suicidal behavior. Neuropsychopharmacology. 1999; 21(2 Suppl):99S-105S. [PubMed: 10432495]

14. Ressler KJ, Nemeroff CB. Role of serotonergic and noradrenergic systems in the pathophysiology of depression and anxiety disorders. Depress Anxiety. 2000; 12(Suppl 1):2-19. [PubMed: 11098410]

15. Blier P. Norepinephrine and selective norepinephrine reuptake inhibitors in depression and mood disorders: their pivotal roles. J Psychiatry Neurosci. 2001; 26(Suppl):S1-S2. [PubMed: 11590963]

16. Cooper WO, et al. Increasing use of antidepressants in pregnancy. American journal of obstetrics and gynecology. 2007; 196(6):544 e1-545 e5. [PubMed: 17547888]

17. Emslie G, Judge R. Tricyclic antidepressants and selective serotonin reuptake inhibitors: use during pregnancy, in children/adolescents and in the elderly. Acta psychiatrica Scandinavica. Supplementum. 2000; 403:26-34. [PubMed: 11019932]

18. Andrade SE, et al. Use of antidepressant medications during pregnancy: a multisite study. American journal of obstetrics and gynecology. 2008; 198(2):194 e1-194 e5. [PubMed: 17905176]

19. Bakker MK, et al. Increase in use of selective serotonin reuptake inhibitors in pregnancy during the last decade, a population-based cohort study from the Netherlands. British journal of clinical pharmacology. 2008; 65(4):600-606. [PubMed: 17953715]

20. Kagan J, Snidman N. Early childhood predictors of adult anxiety disorders. Biol Psychiatry. 1999; 46(11):1536-1541. [PubMed: 10599481]

21. Schwartz CE, Snidman N, Kagan J. Adolescent social anxiety as an outcome of inhibited temperament in childhood. J Am Acad Child Adolesc Psychiatry. 1999; 38(8):1008-1015. [PubMed: 10434493]

22. Moffitt TE, et al. Depression and generalized anxiety disorder: cumulative and sequential comorbidity in a birth cohort followed prospectively to age 32 years. Archives of General Psychiatry. 2007; 64(6):651-660. [PubMed: 17548747]

23. Feng X, et al. Emotion regulation in preschoolers: the roles of behavioral inhibition, maternal affective behavior, and maternal depression. J Child Psychol Psychiatry. 2008; 49(2):132-141. [PubMed: 18211275]

24. Bos K, et al. Psychiatric outcomes in young children with a history of institutionalization. Harv Rev Psychiatry. 2011; 19(1):15-24. [PubMed: 21250893]

25. Eluvathingal TJ, et al. Abnormal brain connectivity in children after early severe socioemotional deprivation: a diffusion tensor imaging study. Pediatrics. 2006; 117(6):2093-2100. [PubMed: 16740852]

26. MacLean K. The impact of institutionalization on child development. Dev Psychopathol. 2003; 15(4):853-884. [PubMed: 14984130]

27. Sheridan M, et al. Early institutionalization: neurobiological consequences and genetic modifiers. Neuropsychol Rev. 2010; 20(4):414-429. [PubMed: 21042937] 
28. Oberlander TF, et al. Prenatal effects of selective serotonin reuptake inhibitor antidepressants, serotonin transporter promoter genotype (SLC6A4), and maternal mood on child behavior at 3 years of age. Archives of pediatrics \& adolescent medicine. 2010; 164(5):444-451. [PubMed: 20439795]

29. Klinger G, et al. Long-term outcome following selective serotonin reuptake inhibitor induced neonatal abstinence syndrome. Journal of perinatology : official journal of the California Perinatal Association. 2011; 31(9):615-620. [PubMed: 21311497]

30. Croen LA, et al. Antidepressant use during pregnancy and childhood autism spectrum disorders. Archives of general psychiatry. 2011; 68(11):1104-1112. [PubMed: 21727247]

31. Rai D, et al. Parental depression, maternal antidepressant use during pregnancy, and risk of autism spectrum disorders: population based case-control study. BMJ. 2013; 346:f2059. [PubMed: 23604083]

32. Harrington RA, et al. Serotonin hypothesis of autism: implications for selective serotonin reuptake inhibitor use during pregnancy. Autism Res. 2013; 6(3):149-168. [PubMed: 23495208]

33. Hermansen TK, et al. Behavior and inhibitory control in children with prenatal exposure to antidepressants and medically untreated depression. Psychopharmacology (Berl). 2016; 233(8): 1523-1535. [PubMed: 26924747]

34. Malm H, B A, Gissler M, Gyllenberg D, Hinkka-Yli-Salomäki S, McKeague IW, Weissman M, Wickramaratne P, Artama M, Gingrich JA, Sourander A. Gestational Exposure to Selective Serotonin Reuptake Inhibitors and Offspring Psychiatric Disorders: A National Register-Based Study. Journal of the American Academy of Child \& Adolescent Psychiatry. 2016

35. Mirmiran M, et al. Suppression of active sleep by chronic treatment with chlorimipramine during early postnatal development: effects upon adult sleep and behavior in the rat. Brain research. 1981; 204(1):129-146. [PubMed: 7195762]

36. Hilakivi LA, Hilakivi I. Increased adult behavioral 'despair' in rats neonatally exposed to desipramine or zimeldine: an animal model of depression? Pharmacology, biochemistry, and behavior. 1987; 28(3):367-369.

37. Vogel G, et al. A new animal model of endogenous depression: a summary of present findings. Neuroscience and biobehavioral reviews. 1990; 14(1):85-91. [PubMed: 2183099]

38. Velazquez-Moctezuma J, Diaz Ruiz O. Neonatal treatment with clomipramine increased immobility in the forced swim test: an attribute of animal models of depression. Pharmacology, biochemistry, and behavior. 1992; 42(4):737-739.

39. Hansen HH, Sanchez C, Meier E. Neonatal administration of the selective serotonin reuptake inhibitor Lu 10-134-C increases forced swimming-induced immobility in adult rats: a putative animal model of depression? The Journal of pharmacology and experimental therapeutics. 1997; 283(3):1333-1341. [PubMed: 9400008]

40. Ansorge MS, et al. Early-life blockade of the 5-HT transporter alters emotional behavior in adult mice. Science. 2004; 306(5697):879-881. [PubMed: 15514160]

41. Hartley PS, et al. Food-entrained rhythmic expression of PER2 and BMAL1 in murine megakaryocytes does not correlate with circadian rhythms in megakaryopoiesis. J Thromb Haemost. 2008; 6(7):1144-1152. [PubMed: 18419744]

42. Maciag D, et al. Neonatal antidepressant exposure has lasting effects on behavior and serotonin circuitry. Neuropsychopharmacology. 2006; 31(1):47-57. [PubMed: 16012532]

43. Popa $\mathrm{D}$, et al. Lasting syndrome of depression produced by reduction in serotonin uptake during postnatal development: evidence from sleep, stress, and behavior. The Journal of neuroscience : the official journal of the Society for Neuroscience. 2008; 28(14):3546-3554. [PubMed: 18385313]

44. Simpson KL, et al. Perinatal antidepressant exposure alters cortical network function in rodents. Proceedings of the National Academy of Sciences of the United States of America. 2011; 108(45): 18465-18470. [PubMed: 22025710]

45. Ansorge MS, Morelli E, Gingrich JA. Inhibition of serotonin but not norepinephrine transport during development produces delayed, persistent perturbations of emotional behaviors in mice. $\mathrm{J}$ Neurosci. 2008; 28(1):199-207. [PubMed: 18171937] 
46. Berumen LC, et al. Serotonin receptors in hippocampus. Scientific World Journal. 2012; 2012:823493. [PubMed: 22629209]

47. Barnes NM, Sharp T. A review of central 5-HT receptors and their function. Neuropharmacology. 1999; 38(8):1083-1152. [PubMed: 10462127]

48. Blakely RD, et al. Cloning and expression of a functional serotonin transporter from rat brain. Nature. 1991; 354(6348):66-70. [PubMed: 1944572]

49. Jacobs BL, Azmitia EC. Structure and function of the brain serotonin system. Physiological reviews. 1992; 72(1):165-229. [PubMed: 1731370]

50. Lowry, CA., et al. Topographic organization and chemoarchitecture of the dorsal raphe nucleus and the median raphe, in Serotonin and Sleep: Molecular, Functional and Clinical Aspects. Monti, JM., et al., editors. Switzerland: Birkhäuser Verlag; 2008. p. 25-67.

51. Tork I. Anatomy of the serotonergic system. Ann N Y Acad Sci. 1990; 600:9-34. discussion 34-5. [PubMed: 2252340]

52. Cropper EC, Eisenman JS, Azmitia EC. An immunocytochemical study of the serotonergic innervation of the thalamus of the rat. J Comp Neurol. 1984; 224(1):38-50. [PubMed: 6371065]

53. Aitken AR, Tork I. Early development of serotonin-containing neurons and pathways as seen in wholemount preparations of the fetal rat brain. J Comp Neurol. 1988; 274(1):32-47. [PubMed: 3047187]

54. Steinbusch HW. Distribution of serotonin-immunoreactivity in the central nervous system of the rat-cell bodies and terminals. Neuroscience. 1981; 6(4):557-618. [PubMed: 7017455]

55. Parent A, Descarries L, Beaudet A. Organization of ascending serotonin systems in the adult rat brain. A radioautographic study after intraventricular administration of [3H]5-hydroxytryptamine. Neuroscience. 1981; 6(2):115-138. [PubMed: 6164006]

56. Muzerelle A, et al. Conditional anterograde tracing reveals distinct targeting of individual serotonin cell groups (B5-B9) to the forebrain and brainstem. Brain Struct Funct. 2016; 221(1):535-561. [PubMed: 25403254]

57. Behzadi G, et al. Afferents to the median raphe nucleus of the rat: retrograde cholera toxin and wheat germ conjugated horseradish peroxidase tracing, and selective $\mathrm{D}-[3 \mathrm{H}]$ aspartate labelling of possible excitatory amino acid inputs. Neuroscience. 1990; 37(1):77-100. [PubMed: 2243599]

58. Plaznik A, et al. The effect of 5,7-DHT-induced lesions of the median raphe nucleus and chronic desipramine administration upon motor behaviour of rats given intrahippocampal clonidine injection. J Psychopharmacol. 1987; 1(4):258-263. [PubMed: 22159139]

59. Thomas $\mathrm{H}$, et al. Lesion of the median raphe nucleus: a combined behavioral and microdialysis study in rats. Pharmacol Biochem Behav. 2000; 65(1):15-21. [PubMed: 10638630]

60. Bowker RM, et al. Mapping monoaminergic and peptidergic pathways. Prog Clin Biol Res. 1982; 79:115-130. [PubMed: 6124002]

61. Ballion B, et al. Ontogeny of descending serotonergic innervation and evidence for intraspinal 5HT neurons in the mouse spinal cord. Brain Res Dev Brain Res. 2002; 137(1):81-88. [PubMed: 12128257]

62. Martin JA. Preterm births - United States, 2007. MMWR Surveill Summ. 2011; 60(Suppl):78-79.

63. Ghosh M, Pearse DD. The role of the serotonergic system in locomotor recovery after spinal cord injury. Front Neural Circuits. 2014; 8:151. [PubMed: 25709569]

64. Stahl SM. Selectivity of SSRIs: individualising patient care through rational treatment choices. Int J Psychiatry Clin Pract. 2004; 8(Suppl 1):3-10. [PubMed: 24930682]

65. Azmitia EC. Serotonin neurons, neuroplasticity, and homeostasis of neural tissue. Neuropsychopharmacology. 1999; 21(2 Suppl):33S-45S. [PubMed: 10432487]

66. Monti JM. The structure of the dorsal raphe nucleus and its relevance to the regulation of sleep and wakefulness. Sleep Med Rev. 2010; 14(5):307-317. [PubMed: 20153669]

67. Zardetto-Smith AM, Johnson AK. Chemical topography of efferent projections from the median preoptic nucleus to pontine monoaminergic cell groups in the rat. Neurosci Lett. 1995; 199(3): 215-219. [PubMed: 8577401] 
68. Kelly KJ, et al. Swim stress activates serotonergic and nonserotonergic neurons in specific subdivisions of the rat dorsal raphe nucleus in a temperature-dependent manner. Neuroscience. 2011; 197:251-268. [PubMed: 21945646]

69. Bernard R, Veh RW. Individual neurons in the rat lateral habenular complex project mostly to the dopaminergic ventral tegmental area or to the serotonergic raphe nuclei. J Comp Neurol. 2012; 520(11):2545-2558. [PubMed: 22492391]

70. Monti, JM. Serotonin and sleep molecular, functional and clinical aspects. Basel ; Boston: Birkhèauser; 2008.

71. Vertes RP, Kocsis B. Projections of the dorsal raphe nucleus to the brainstem: PHA-L analysis in the rat. J Comp Neurol. 1994; 340(1):11-26. [PubMed: 8176000]

72. Hochstrasser T, et al. Inflammatory stimuli reduce survival of serotonergic neurons and induce neuronal expression of indoleamine 2,3-dioxygenase in rat dorsal raphe nucleus organotypic brain slices. Neuroscience. 2011; 184:128-138. [PubMed: 21501664]

73. Drugan RC, et al. Prior cold water swim stress alters immobility in the forced swim test and associated activation of serotonergic neurons in the rat dorsal raphe nucleus. Neuroscience. 2013; 253:221-234. [PubMed: 23999122]

74. Abrams JK, et al. Anatomic and functional topography of the dorsal raphe nucleus. Ann N Y Acad Sci. 2004; 1018:46-57. [PubMed: 15240351]

75. Spannuth BM, et al. Investigation of a central nucleus of the amygdala/dorsal raphe nucleus serotonergic circuit implicated in fear-potentiated startle. Neuroscience. 2011; 179:104-119. [PubMed: 21277950]

76. Gardner KL, et al. Early life experience alters behavior during social defeat: focus on serotonergic systems. Neuroscience. 2005; 136(1):181-191. [PubMed: 16182451]

77. Lee HS, et al. Glutamatergic afferent projections to the dorsal raphe nucleus of the rat. Brain Res. 2003; 963(1-2):57-71. [PubMed: 12560111]

78. Meloni EG, et al. Activation of raphe efferents to the medial prefrontal cortex by corticotropinreleasing factor: correlation with anxiety-like behavior. Biol Psychiatry. 2008; 63(9):832-839. [PubMed: 18061145]

79. Baker KG, et al. Distribution, morphology and number of monoamine-synthesizing and substance P-containing neurons in the human dorsal raphe nucleus. Neuroscience. 1991; 42(3):757-775. [PubMed: 1720227]

80. Soiza-Reilly M, Commons KG. Glutamatergic drive of the dorsal raphe nucleus. J Chem Neuroanat. 2011; 41(4):247-255. [PubMed: 21550397]

81. Fu W, et al. Chemical neuroanatomy of the dorsal raphe nucleus and adjacent structures of the mouse brain. J Comp Neurol. 2010; 518(17):3464-3494. [PubMed: 20589909]

82. Kiyasova V, et al. A subpopulation of serotonergic neurons that do not express the 5-HT1A autoreceptor. ACS Chem Neurosci. 2013; 4(1):89-95. [PubMed: 23336048]

83. Gaspar P, Lillesaar C. Probing the diversity of serotonin neurons. Philos Trans R Soc Lond B Biol Sci. 2012; 367(1601):2382-2394. [PubMed: 22826339]

84. Hornung JP, Fritschy JM, Tork I. Distribution of two morphologically distinct subsets of serotoninergic axons in the cerebral cortex of the marmoset. J Comp Neurol. 1990; 297(2):165181. [PubMed: 2115053]

85. Hornung JP, Celio MR. The selective innervation by serotoninergic axons of calbindin-containing interneurons in the neocortex and hippocampus of the marmoset. J Comp Neurol. 1992; 320(4): 457-467. [PubMed: 1629398]

86. Beck SG, et al. Median and dorsal raphe neurons are not electrophysiologically identical. J Neurophysiol. 2004; 91(2):994-1005. [PubMed: 14573555]

87. Trulson ME, Frederickson CJ. A comparison of the electrophysiological and pharmacological properties of serotonin-containing neurons in the nucleus raphe dorsalis, raphe medianus and raphe pallidus recorded from mouse brain slices in vitro: role of autoreceptors. Brain Res Bull. 1987; 18(2):179-190. [PubMed: 2436725]

88. Calizo LH, et al. Raphe serotonin neurons are not homogenous: electrophysiological, morphological and neurochemical evidence. Neuropharmacology. 2011; 61(3):524-543. [PubMed: 21530552] 
89. Kocsis B, et al. Serotonergic neuron diversity: identification of raphe neurons with discharges timelocked to the hippocampal theta rhythm. Proc Natl Acad Sci U S A. 2006; 103(4):1059-1064. [PubMed: 16418294]

90. Crawford LK, Craige CP, Beck SG. Increased intrinsic excitability of lateral wing serotonin neurons of the dorsal raphe: a mechanism for selective activation in stress circuits. J Neurophysiol. 2010; 103(5):2652-2663. [PubMed: 20237311]

91. Urbain N, Creamer K, Debonnel G. Electrophysiological diversity of the dorsal raphe cells across the sleep-wake cycle of the rat. J Physiol. 2006; 573(Pt 3):679-695. [PubMed: 16613874]

92. Gocho Y, et al. Electrophysiological and pharmacological properties of GABAergic cells in the dorsal raphe nucleus. J Physiol Sci. 2013; 63(2):147-154. [PubMed: 23275149]

93. Liu R, Jolas T, Aghajanian G. Serotonin 5-HT(2) receptors activate local GABA inhibitory inputs to serotonergic neurons of the dorsal raphe nucleus. Brain Res. 2000; 873(1):34-45. [PubMed: 10915808]

94. Roberts C, et al. GABAergic modulation of 5-HT7 receptor-mediated effects on 5-HT efflux in the guinea-pig dorsal raphe nucleus. Neuropharmacology. 2004; 46(7):935-941. [PubMed: 15081790]

95. Kusek M, et al. 5-HT7 receptor modulates GABAergic transmission in the rat dorsal raphe nucleus and controls cortical release of serotonin. Front Cell Neurosci. 2015; 9:324. [PubMed: 26347612]

96. Gervasoni D, et al. Role and origin of the GABAergic innervation of dorsal raphe serotonergic neurons. J Neurosci. 2000; 20(11):4217-4225. [PubMed: 10818157]

97. Ahlemeyer B, et al. S-100beta protects cultured neurons against glutamate- and staurosporineinduced damage and is involved in the antiapoptotic action of the 5 HT(1A)-receptor agonist, Bay $\times$ 3702. Brain Res. 2000; 858(1):121-128. [PubMed: 10700604]

98. Whitaker-Azmitia PM. Serotonin and brain development: role in human developmental diseases. Brain Res Bull. 2001; 56(5):479-485. [PubMed: 11750793]

99. Van Hartesveldt C, Moore B, Hartman BK. Transient midline raphe glial structure in the developing rat. J Comp Neurol. 1986; 253(2):174-184. [PubMed: 3540038]

100. Kalen P, Karlson M, Wiklund L. Possible excitatory amino acid afferents to nucleus raphe dorsalis of the rat investigated with retrograde wheat germ agglutinin and $\mathrm{D}-[3 \mathrm{H}]$ aspartate tracing. Brain Res. 1985; 360(1-2):285-297. [PubMed: 2866825]

101. Bonnin A, et al. A transient placental source of serotonin for the fetal forebrain. Nature. 2011; 472(7343):347-350. [PubMed: 21512572]

102. Oberlander TF, Gingrich JA, Ansorge MS. Sustained neurobehavioral effects of exposure to SSRI antidepressants during development: molecular to clinical evidence. Clinical pharmacology and therapeutics. 2009; 86(6):672-677. [PubMed: 19890255]

103. Foote SL, Morrison JH. Development of the noradrenergic, serotonergic, and dopaminergic innervation of neocortex. Curr Top Dev Biol. 1987; 21:391-423. [PubMed: 3308332]

104. Puelles L, et al. A developmental ontology for the mammalian brain based on the prosomeric model. Trends Neurosci. 2013; 36(10):570-578. [PubMed: 23871546]

105. Jensen P, et al. Redefining the serotonergic system by genetic lineage. Nat Neurosci. 2008; 11(4): 417-419. [PubMed: 18344997]

106. Gaspar P, Cases O, Maroteaux L. The developmental role of serotonin: news from mouse molecular genetics. Nature reviews. Neuroscience. 2003; 4(12):1002-1012. [PubMed: 14618156]

107. Ye W, et al. FGF and Shh signals control dopaminergic and serotonergic cell fate in the anterior neural plate. Cell. 1998; 93(5):755-766. [PubMed: 9630220]

108. Hynes M, et al. The seven-transmembrane receptor smoothened cell-autonomously induces multiple ventral cell types. Nat Neurosci. 2000; 3(1):41-46. [PubMed: 10607393]

109. Craven SE, et al. Gata2 specifies serotonergic neurons downstream of sonic hedgehog. Development. 2004; 131(5):1165-1173. [PubMed: 14973276]

110. Alenina N, Bashammakh S, Bader M. Specification and differentiation of serotonergic neurons. Stem Cell Rev. 2006; 2(1):5-10. [PubMed: 17142880]

111. Pattyn A, et al. Ascl1/Mash1 is required for the development of central serotonergic neurons. Nat Neurosci. 2004; 7(6):589-595. [PubMed: 15133515] 
112. Hendricks T, et al. The ETS domain factor Pet-1 is an early and precise marker of central serotonin neurons and interacts with a conserved element in serotonergic genes. J Neurosci. 1999; 19(23):10348-10356. [PubMed: 10575032]

113. Lidov HG, Molliver ME. An immunohistochemical study of serotonin neuron development in the rat: ascending pathways and terminal fields. Brain Res Bull. 1982; 8(4):389-430. [PubMed: 6178481]

114. Gutknecht L, et al. Spatio-temporal expression of tryptophan hydroxylase isoforms in murine and human brain: convergent data from Tph2 knockout mice. Eur Neuropsychopharmacol. 2009; 19(4):266-282. [PubMed: 19181488]

115. Teitelman G, et al. Expression of amino acid decarboxylase in proliferating cells of the neural tube and notochord of developing rat embryo. J Neurosci. 1983; 3(7):1379-1388. [PubMed: 6864253]

116. Mamounas LA, et al. Brain-derived neurotrophic factor promotes the survival and sprouting of serotonergic axons in rat brain. J Neurosci. 1995; 15(12):7929-7939. [PubMed: 8613731]

117. Nishi M, Kawata M, Azmitia EC. Trophic interactions between brain-derived neurotrophic factor and s100beta on cultured serotonergic neurons. Brain Res. 2000; 868(1):113-118. [PubMed: 10841894]

118. Galter D, Unsicker K. Brain-derived neurotrophic factor and trkB are essential for cAMPmediated induction of the serotonergic neuronal phenotype. J Neurosci Res. 2000; 61(3):295301. [PubMed: 10900076]

119. Whitaker-Azmitia PM, Azmitia EC. Stimulation of astroglial serotonin receptors produces culture media which regulates growth of serotonergic neurons. Brain Res. 1989; 497(1):80-85. [PubMed: 2790458]

120. Azmitia EC, et al. 5-HT1A agonist and dexamethasone reversal of parachloroamphetamine induced loss of MAP-2 and synaptophysin immunoreactivity in adult rat brain. Brain Res. 1995; 677(2):181-192. [PubMed: 7552242]

121. Haring $\mathrm{JH}$, et al. Hippocampal serotonin levels influence the expression of S100 beta detected by immunocytochemistry. Brain Res. 1993; 631(1):119-123. [PubMed: 8298984]

122. Whitaker-Azmitia PM, Murphy R, Azmitia EC. Stimulation of astroglial 5-HT1A receptors releases the serotonergic growth factor, protein S-100, and alters astroglial morphology. Brain Res. 1990; 528(1):155-158. [PubMed: 2245332]

123. Kinney GG, Vogel GW, Feng P. Decreased dorsal raphe nucleus neuronal activity in adult chloral hydrate anesthetized rats following neonatal clomipramine treatment: implications for endogenous depression. Brain research. 1997; 756(1-2):68-75. [PubMed: 9187315]

124. Weaver KJ, et al. Neonatal exposure to citalopram selectively alters the expression of the serotonin transporter in the hippocampus: dose-dependent effects. Anatomical record. 2010; 293(11):1920-1932.

125. Migliarini S, et al. Lack of brain serotonin affects postnatal development and serotonergic neuronal circuitry formation. Mol Psychiatry. 2013; 18(10):1106-1118. [PubMed: 23007167]

126. Feenstra MG, et al. Decreased hypothalamic serotonin levels in adult rats treated neonatally with clomipramine. Pharmacol Biochem Behav. 1996; 55(4):647-652. [PubMed: 8981596]

127. Vijayakumar M, Meti BL. Alterations in the levels of monoamines in discrete brain regions of clomipramine-induced animal model of endogenous depression. Neurochem Res. 1999; 24(3): 345-349. [PubMed: 10215507]

128. Yannielli PC, et al. Effects of neonatal clomipramine treatment on locomotor activity, anxietyrelated behavior and serotonin turnover in Syrian hamsters. Neuropsychobiology. 1999; 39(4): 200-206. [PubMed: 10343185]

129. Zhou FC, Sari Y, Zhang JK. Expression of serotonin transporter protein in developing rat brain. Brain Res Dev Brain Res. 2000; 119(1):33-45. [PubMed: 10648870]

130. Lebrand C, et al. Transient developmental expression of monoamine transporters in the rodent forebrain. J Comp Neurol. 1998; 401(4):506-524. [PubMed: 9826275]

131. Lauder JM, Krebs H. Serotonin as a differentiation signal in early neurogenesis. Dev Neurosci. 1978; 1(1):15-30. [PubMed: 158519] 
132. Hole K. Behavior and brain growth in rats treated with p-chlorophenylalanine in the first weeks of life. Dev Psychobiol. 1972; 5(2):157-173. [PubMed: 4276421]

133. Mazer C, et al. Serotonin depletion during synaptogenesis leads to decreased synaptic density and learning deficits in the adult rat: a possible model of neurodevelopmental disorders with cognitive deficits. Brain Res. 1997; 760(1-2):68-73. [PubMed: 9237519]

134. Yan W, Wilson CC, Haring JH. Effects of neonatal serotonin depletion on the development of rat dentate granule cells. Brain Res Dev Brain Res. 1997; 98(2):177-184. [PubMed: 9051258]

135. Vitalis T, et al. Embryonic depletion of serotonin affects cortical development. Eur J Neurosci. 2007; 26(2):331-344. [PubMed: 17650110]

136. Moiseiwitsch JR, Lauder JM. Serotonin regulates mouse cranial neural crest migration. Proc Natl Acad Sci U S A. 1995; 92(16):7182-7186. [PubMed: 7638165]

137. Mower GD. Comparison of serotonin 5-HT1 receptors and innervation in the visual cortex of normal and dark-reared cats. J Comp Neurol. 1991; 312(2):223-230. [PubMed: 1748729]

138. Nishi M, Azmitia EC. 5-HT1A receptor expression is modulated by corticosteroid receptor agonists in primary rat hippocampal culture. Brain Res. 1996; 722(1-2):190-194. [PubMed: 8813366]

139. Riad M, Emerit MB, Hamon M. Neurotrophic effects of ipsapirone and other 5-HT1A receptor agonists on septal cholinergic neurons in culture. Brain Res Dev Brain Res. 1994; 82(1-2):245258. [PubMed: 7842512]

140. Blue ME, Erzurumlu RS, Jhaveri S. A comparison of pattern formation by thalamocortical and serotonergic afferents in the rat barrel field cortex. Cereb Cortex. 1991; 1(5):380-389. [PubMed: 1822748]

141. Leslie MJ, Bennett-Clarke CA, Rhoades RW. Serotonin 1B receptors form a transient vibrissarelated pattern in the primary somatosensory cortex of the developing rat. Brain Res Dev Brain Res. 1992; 69(1):143-148. [PubMed: 1424087]

142. Rhoades RW, et al. Effects of 5-HT on thalamocortical synaptic transmission in the developing rat. J Neurophysiol. 1994; 72(5):2438-2450. [PubMed: 7884470]

143. Azmitia EC, et al. S100 beta and serotonin: a possible astrocytic-neuronal link to neuropathology of Alzheimer's disease. Prog Brain Res. 1992; 94:459-473. [PubMed: 1287730]

144. Mathews TA, et al. Gene dose-dependent alterations in extraneuronal serotonin but not dopamine in mice with reduced serotonin transporter expression. J Neurosci Methods. 2004; 140(1-2):169181. [PubMed: 15589347]

145. Altamura C, et al. Altered neocortical cell density and layer thickness in serotonin transporter knockout mice: a quantitation study. Cereb Cortex. 2007; 17(6):1394-1401. [PubMed: 16905592]

146. Riccio O, et al. Excess of serotonin affects embryonic interneuron migration through activation of the serotonin receptor 6. Mol Psychiatry. 2009; 14(3):280-290. [PubMed: 18663366]

147. Riccio O, et al. Excess of serotonin affects neocortical pyramidal neuron migration. Transl Psychiatry. 2011; 1:e47. [PubMed: 22833193]

148. Rebello TJ, et al. Postnatal day 2 to 11 constitutes a 5-HT-sensitive period impacting adult mPFC function. J Neurosci. 2014; 34(37):12379-12393. [PubMed: 25209278]

149. Liao CC, Lee LJ. Neonatal fluoxetine exposure affects the action potential properties and dendritic development in cortical subplate neurons of rats. Toxicol Lett. 2011; 207(3):314-321. [PubMed: 21986067]

150. Cases O, et al. Lack of barrels in the somatosensory cortex of monoamine oxidase A-deficient mice: role of a serotonin excess during the critical period. Neuron. 1996; 16(2):297-307. [PubMed: 8789945]

151. Cases O, et al. Plasma membrane transporters of serotonin, dopamine, and norepinephrine mediate serotonin accumulation in atypical locations in the developing brain of monoamine oxidase A knock-outs. J Neurosci. 1998; 18(17):6914-6927. [PubMed: 9712661]

152. Xu Y, Sari Y, Zhou FC. Selective serotonin reuptake inhibitor disrupts organization of thalamocortical somatosensory barrels during development. Brain Res Dev Brain Res. 2004; 150(2):151-161. [PubMed: 15158078] 
153. Lee LJ. Neonatal fluoxetine exposure affects the neuronal structure in the somatosensory cortex and somatosensory-related behaviors in adolescent rats. Neurotox Res. 2009; 15(3):212-223. [PubMed: 19384594]

154. Hanley GE, Brain U, Oberlander TF. Infant developmental outcomes following prenatal exposure to antidepressants, and maternal depressed mood and positive affect. Early Hum Dev. 2013; 89(8):519-524. [PubMed: 23384962]

155. Hanley GE, Brain U, Oberlander TF. Prenatal exposure to serotonin reuptake inhibitor antidepressants and childhood behavior. Pediatr Res. 2015; 78(2):174-180. [PubMed: 25897539]

156. Kepser LJ, Homberg JR. The neurodevelopmental effects of serotonin: a behavioural perspective. Behav Brain Res. 2015; 277:3-13. [PubMed: 24859172]

157. Patkar AA, Bilal L, Masand PS. Pharmacotherapy of depression in pregnancy. Ann Clin Psychiatry. 2004; 16(2):87-100. [PubMed: 15328902]

158. Kallen B, Otterblad Olausson P. Antidepressant drugs during pregnancy and infant congenital heart defect. Reprod Toxicol. 2006; 21(3):221-222. [PubMed: 16406480]

159. Bar-Oz B, et al. Paroxetine and congenital malformations: meta-Analysis and consideration of potential confounding factors. Clin Ther. 2007; 29(5):918-926. [PubMed: 17697910]

160. Ellfork M, M H. Risks associated with in utero and lactation exposure to selective serotonin reuptake inhibitors (SSRIs). Reprod Toxicol. 2010; 30(2):249-260. [PubMed: 20447455]

161. Diav-Citrin O, et al. Paroxetine and fluoxetine in pregnancy: a prospective, multicentre, controlled, observational study. Br J Clin Pharmacol. 2008; 66(5):695-705. [PubMed: 18754846]

162. Jimenez-Solem E, et al. Exposure to selective serotonin reuptake inhibitors and the risk of congenital malformations: a nationwide cohort study. BMJ Open. 2012; 2(3)

163. Pedersen LH, et al. Selective serotonin reuptake inhibitors in pregnancy and congenital malformations: population based cohort study. BMJ. 2009; 339:b3569. [PubMed: 19776103]

164. Louik C, et al. First-trimester use of selective serotonin-reuptake inhibitors and the risk of birth defects. N Engl J Med. 2007; 356(26):2675-2683. [PubMed: 17596601]

165. Kornum JB, et al. Use of selective serotonin-reuptake inhibitors during early pregnancy and risk of congenital malformations: updated analysis. Clin Epidemiol. 2010; 2:29-36. [PubMed: 20865100]

166. Berard A, et al. First trimester exposure to paroxetine and risk of cardiac malformations in infants: the importance of dosage. Birth Defects Res B Dev Reprod Toxicol. 2007; 80(1):18-27. [PubMed: 17187388]

167. Cole JA, et al. Paroxetine in the first trimester and the prevalence of congenital malformations. Pharmacoepidemiol Drug Saf. 2007; 16(10):1075-1085. [PubMed: 17729379]

168. Einarson A, et al. Evaluation of the risk of congenital cardiovascular defects associated with use of paroxetine during pregnancy. Am J Psychiatry. 2008; 165(6):749-752. [PubMed: 18381907]

169. Oberlander TF, et al. Infant serotonin transporter (SLC6A4) promoter genotype is associated with adverse neonatal outcomes after prenatal exposure to serotonin reuptake inhibitor medications. Molecular psychiatry. 2008; 13(1):65-73. [PubMed: 17519929]

170. Wogelius P, et al. Maternal use of selective serotonin reuptake inhibitors and risk of congenital malformations. Epidemiology. 2006; 17(6):701-704. [PubMed: 17028507]

171. Alwan S, et al. Use of selective serotonin-reuptake inhibitors in pregnancy and the risk of birth defects. N Engl J Med. 2007; 356(26):2684-2692. [PubMed: 17596602]

172. Bakker MK, et al. First-trimester use of paroxetine and congenital heart defects: a populationbased case-control study. Birth Defects Res A Clin Mol Teratol. 2010; 88(2):94-100. [PubMed: 19937603]

173. Oberlander TF, et al. Neonatal outcomes after prenatal exposure to selective serotonin reuptake inhibitor antidepressants and maternal depression using population-based linked health data. Arch Gen Psychiatry. 2006; 63(8):898-906. [PubMed: 16894066]

174. El Marroun H, et al. Maternal use of selective serotonin reuptake inhibitors, fetal growth, and risk of adverse birth outcomes. Arch Gen Psychiatry. 2012; 69(7):706-714. [PubMed: 22393202]

175. Lund N, Pedersen LH, Henriksen TB. Selective serotonin reuptake inhibitor exposure in utero and pregnancy outcomes. Arch Pediatr Adolesc Med. 2009; 163(10):949-954. [PubMed: 19805715] 
176. Hayes RM, et al. Maternal antidepressant use and adverse outcomes: a cohort study of 228,876 pregnancies. American journal of obstetrics and gynecology. 2012; 207(1):49 e1-49 e9. [PubMed: 22727349]

177. Zeskind PS, Stephens LE. Maternal selective serotonin reuptake inhibitor use during pregnancy and newborn neurobehavior. Pediatrics. 2004; 113(2):368-375. [PubMed: 14754951]

178. Alwan S, Friedman JM. Safety of selective serotonin reuptake inhibitors in pregnancy. CNS drugs. 2009; 23(6):493-509. [PubMed: 19480468]

179. Gentile S, Galbally M. Prenatal exposure to antidepressant medications and neurodevelopmental outcomes: a systematic review. Journal of affective disorders. 2011; 128(1-2):1-9. [PubMed: 20303599]

180. Oberlander TF, et al. Pain reactivity in 2-month-old infants after prenatal and postnatal serotonin reuptake inhibitor medication exposure. Pediatrics. 2005; 115(2):411-425. [PubMed: 15687451]

181. Levinson-Castiel R, et al. Neonatal abstinence syndrome after in utero exposure to selective serotonin reuptake inhibitors in term infants. Arch Pediatr Adolesc Med. 2006; 160(2):173-176. [PubMed: 16461873]

182. Klinger G, Merlob P. Selective serotonin reuptake inhibitor induced neonatal abstinence syndrome. Isr J Psychiatry Relat Sci. 2008; 45(2):107-113. [PubMed: 18982836]

183. Heils A, et al. Allelic variation of human serotonin transporter gene expression. J Neurochem. 1996; 66(6):2621-2624. [PubMed: 8632190]

184. Lesch KP, et al. Association of anxiety-related traits with a polymorphism in the serotonin transporter gene regulatory region. Science. 1996; 274(5292):1527-1531. [PubMed: 8929413]

185. Oberlander TF, et al. Prolonged prenatal psychotropic medication exposure alters neonatal acute pain response. Pediatr Res. 2002; 51(4):443-453. [PubMed: 11919328]

186. Oberlander TF, et al. Hypothalamic-pituitary-adrenal (HPA) axis function in 3-month old infants with prenatal selective serotonin reuptake inhibitor (SSRI) antidepressant exposure. Early human development. 2008; 84(10):689-697. [PubMed: 18639992]

187. Pawluski JL, et al. Prenatal SSRI exposure alters neonatal corticosteroid binding globulin, infant cortisol levels, and emerging HPA function. Psychoneuroendocrinology. 2012; 37(7):1019-1028. [PubMed: 22177580]

188. Brandlistuen RE, et al. Behavioural effects of fetal antidepressant exposure in a Norwegian cohort of discordant siblings. Int J Epidemiol. 2015; 44(4):1397-1407. [PubMed: 25873178]

189. Figueroa R. Use of antidepressants during pregnancy and risk of attention-deficit/hyperactivity disorder in the offspring. J Dev Behav Pediatr. 2010; 31(8):641-648. [PubMed: 20613624]

190. Misri S, et al. Internalizing behaviors in 4-year-old children exposed in utero to psychotropic medications. Am J Psychiatry. 2006; 163(6):1026-1032. [PubMed: 16741203]

191. Weikum WM, et al. Prenatal exposure to antidepressants and depressed maternal mood alter trajectory of infant speech perception. Proc Natl Acad Sci U S A. 2012; 109(Suppl 2):1722117227. [PubMed: 23045665]

192. Weikum WM, et al. The impact of prenatal serotonin reuptake inhibitor (SRI) antidepressant exposure and maternal mood on mother-infant interactions at 3 months of age. Infant Behav Dev. 2013; 36(4):485-493. [PubMed: 23728194]

193. Eriksen HL, et al. No association between prenatal exposure to psychotropics and intelligence at age five. Acta Obstet Gynecol Scand. 2015; 94(5):501-507. [PubMed: 25711407]

194. Nulman I, et al. Neurodevelopment of children exposed in utero to antidepressant drugs. N Engl J Med. 1997; 336(4):258-262. [PubMed: 8995088]

195. Nulman I, et al. Child development following exposure to tricyclic antidepressants or fluoxetine throughout fetal life: a prospective, controlled study. Am J Psychiatry. 2002; 159(11):1889-1895. [PubMed: 12411224]

196. Nulman I, et al. Neurodevelopment of children following prenatal exposure to venlafaxine, selective serotonin reuptake inhibitors, or untreated maternal depression. Am J Psychiatry. 2012; 169(11):1165-1174. [PubMed: 23128923]

197. Weikum WM, et al. Prenatal serotonin reuptake inhibitor (SRI) antidepressant exposure and serotonin transporter promoter genotype (SLC6A4) influence executive functions at 6 years of age. Front Cell Neurosci. 2013; 7:180. [PubMed: 24130516] 
198. Man KK, et al. Exposure to selective serotonin reuptake inhibitors during pregnancy and risk of autism spectrum disorder in children: a systematic review and meta-analysis of observational studies. Neurosci Biobehav Rev. 2015; 49:82-89. [PubMed: 25498856]

199. Gentile S. Prenatal antidepressant exposure and the risk of autism spectrum disorders in children. Are we looking at the fall of Gods? J Affect Disord. 2015; 182:132-137. [PubMed: 25985383]

200. Muller CL, Anacker AM, Veenstra-VanderWeele J. The serotonin system in autism spectrum disorder: From biomarker to animal models. Neuroscience. 2015

201. Boukhris T, et al. Antidepressant Use During Pregnancy and the Risk of Autism Spectrum Disorder in Children. JAMA Pediatr. 2015:1-8.

202. Harrington RA, et al. Prenatal SSRI use and offspring with autism spectrum disorder or developmental delay. Pediatrics. 2014; 133(5):e1241-e1248. [PubMed: 24733881]

203. Gidaya NB, et al. In utero exposure to selective serotonin reuptake inhibitors and risk for autism spectrum disorder. J Autism Dev Disord. 2014; 44(10):2558-2567. [PubMed: 24803368]

204. Rodriguez-Porcel F, et al. Neonatal exposure of rats to antidepressants affects behavioral reactions to novelty and social interactions in a manner analogous to autistic spectrum disorders. Anatomical record. 2011; 294(10):1726-1735.

205. Olivier JD, et al. The age-dependent effects of selective serotonin reuptake inhibitors in humans and rodents: A review. Progress in neuro-psychopharmacology \& biological psychiatry. 2011; 35(6):1400-1408. [PubMed: 20883714]

206. Sarkar A, Chachra P, Vaidya VA. Postnatal fluoxetine-evoked anxiety is prevented by concomitant 5-HT2A/C receptor blockade and mimicked by postnatal 5-HT2A/C receptor stimulation. Biol Psychiatry. 2014; 76(11):858-868. [PubMed: 24315410]

207. Zimmerberg B, Germeyan SC. Effects of neonatal fluoxetine exposure on behavior across development in rats selectively bred for an infantile affective trait. Dev Psychobiol. 2015; 57(2): 141-152. [PubMed: 25503615]

208. Harris SS, et al. Dose-dependent effects of neonatal SSRI exposure on adult behavior in the rat. Brain Res. 2012; 1429:52-60. [PubMed: 22079319]

209. Rayen I, et al. Developmental fluoxetine exposure facilitates sexual behavior in female offspring. Psychopharmacology (Berl). 2014; 231(1):123-133. [PubMed: 23900642]

210. Soga T, et al. Early-life citalopram-induced impairments in sexual behavior and the role of androgen receptor. Neuroscience. 2012; 225:172-184. [PubMed: 22960312]

211. Maciag D, Coppinger D, Paul IA. Evidence that the deficit in sexual behavior in adult rats neonatally exposed to citalopram is a consequence of 5-HT1 receptor stimulation during development. Brain Res. 2006; 1125(1):171-175. [PubMed: 17101120]

212. Maciag D, et al. Neonatal citalopram exposure produces lasting changes in behavior which are reversed by adult imipramine treatment. Eur J Pharmacol. 2006; 532(3):265-269. [PubMed: 16483567]

213. Lisboa SF, et al. Behavioral evaluation of male and female mice pups exposed to fluoxetine during pregnancy and lactation. Pharmacology. 2007; 80(1):49-56. [PubMed: 17519559]

214. Manhaes de Castro R, et al. Reduction of intraspecific aggression in adult rats by neonatal treatment with a selective serotonin reuptake inhibitor. Braz J Med Biol Res. 2001; 34(1):121124. [PubMed: 11151037]

215. Bairy KL, et al. Developmental and behavioral consequences of prenatal fluoxetine. Pharmacology. 2007; 79(1):1-11. [PubMed: 17077648]

216. McAllister BB, Kiryanova V, Dyck RH. Behavioural outcomes of perinatal maternal fluoxetine treatment. Neuroscience. 2012; 226:356-366. [PubMed: 23000627]

217. Rodgers RJ, Dalvi A. Anxiety, defence and the elevated plus-maze. Neurosci Biobehav Rev. 1997; 21(6):801-810. [PubMed: 9415905]

218. Shephard RA, Broadhurst PL. Effects of diazepam and of serotonin agonists on hyponeophagia in rats. Neuropharmacology. 1982; 21(4):337-340. [PubMed: 7088266]

219. Lee LJ, Lee LJ. Neonatal fluoxetine exposure alters motor performances of adolescent rats. Dev Neurobiol. 2012; 72(8):1122-1132. [PubMed: 21714104] 
220. Karpova NN, et al. Long-lasting behavioural and molecular alterations induced by early postnatal fluoxetine exposure are restored by chronic fluoxetine treatment in adult mice. European neuropsychopharmacology : the journal of the European College of Neuropsychopharmacology. 2009; 19(2):97-108. [PubMed: 18973993]

221. Toffoli LV, et al. Maternal exposure to fluoxetine during gestation and lactation affects the DNA methylation programming of rat's offspring: modulation by folic acid supplementation. Behav Brain Res. 2014; 265:142-147. [PubMed: 24583191]

222. Knaepen L, et al. Developmental fluoxetine exposure normalizes the long-term effects of maternal stress on post-operative pain in Sprague-Dawley rat offspring. PLoS One. 2013; 8(2):e57608. [PubMed: 23437400]

223. Glover ME, et al. Early-life exposure to the SSRI paroxetine exacerbates depression-like behavior in anxiety/depression-prone rats. Neuroscience. 2015; 284:775-797. [PubMed: 25451292]

224. Rayen I, et al. Fluoxetine during development reverses the effects of prenatal stress on depressivelike behavior and hippocampal neurogenesis in adolescence. PloS one. 2011; 6(9):e24003. [PubMed: 21912658]

225. Boulle F, et al. Developmental fluoxetine exposure increases behavioral despair and alters epigenetic regulation of the hippocampal BDNF gene in adult female offspring. Horm Behav. 2016

226. Zohar I, Shoham S, Weinstock M. Perinatal citalopram does not prevent the effect of prenatal stress on anxiety, depressive-like behaviour and serotonergic transmission in adult rat offspring. Eur J Neurosci. 2015

227. Porsolt RD, Le Pichon M, Jalfre M. Depression: a new animal model sensitive to antidepressant treatments. Nature. 1977; 266(5604):730-732. [PubMed: 559941]

228. Cryan JF, Valentino RJ, Lucki I. Assessing substrates underlying the behavioral effects of antidepressants using the modified rat forced swimming test. Neurosci Biobehav Rev. 2005; 29(4-5):547-569. [PubMed: 15893822]

229. Petit-Demouliere B, Chenu F, Bourin M. Forced swimming test in mice: a review of antidepressant activity. Psychopharmacology (Berl). 2005; 177(3):245-255. [PubMed: 15609067]

230. Bhagya $\mathrm{V}$, et al. The selective noradrenergic reuptake inhibitor reboxetine restores spatial learning deficits, biochemical changes, and hippocampal synaptic plasticity in an animal model of depression. J Neurosci Res. 2015; 93(1):104-120. [PubMed: 25146499]

231. Yang LM, et al. Lateral habenula lesions improve the behavioral response in depressed rats via increasing the serotonin level in dorsal raphe nucleus. Behav Brain Res. 2008; 188(1):84-90. [PubMed: 18054396]

232. Vazquez-Palacios G, Bonilla-Jaime H, Velazquez-Moctezuma J. Antidepressant effects of nicotine and fluoxetine in an animal model of depression induced by neonatal treatment with clomipramine. Prog Neuropsychopharmacol Biol Psychiatry. 2005; 29(1):39-46. [PubMed: 15610943]

233. Limon-Morales O, et al. Altered expression of 5-HT1A receptors in adult rats induced by neonatal treatment with clomipramine. Physiol Behav. 2014; 124:37-44. [PubMed: 24211235]

234. Coleman FH, et al. Behavioral changes in developing mice after prenatal exposure to paroxetine (Paxil). Am J Obstet Gynecol. 1999; 181(5 Pt 1):1166-1171. [PubMed: 10561639]

235. Olivier JD, et al. Fluoxetine administration to pregnant rats increases anxiety-related behavior in the offspring. Psychopharmacology (Berl). 2011; 217(3):419-432. [PubMed: 21487650]

236. Mendes-da-Silva C, et al. Neonatal treatment with fluoxetine reduces depressive behavior induced by forced swim in adult rats. Arq Neuropsiquiatr. 2002; 60(4):928-931. [PubMed: 12563382]

237. Wellman CL, et al. Impaired stress-coping and fear extinction and abnormal corticolimbic morphology in serotonin transporter knock-out mice. J Neurosci. 2007; 27(3):684-691. [PubMed: 17234600]

238. Binder E, et al. Antidepressants and the resilience to early-life stress in inbred mouse strains. Pharmacogenet Genomics. 2011; 21(12):779-789. [PubMed: 22016050] 
239. Kabbaj M. Neurobiological bases of individual differences in emotional and stress responsiveness: high responders-low responders model. Archives of Neurology. 2004; 61(7): 1009-1012. [PubMed: 15262729]

240. Piazza PV, et al. Factors that predict individual vulnerability to amphetamine self-administration. Science. 1989; 245(4925):1511-1513. [PubMed: 2781295]

241. Beiderbeck DI, Neumann ID, Veenema AH. Differences in intermale aggression are accompanied by opposite vasopressin release patterns within the septum in rats bred for low and high anxiety. Eur J Neurosci. 2007; 26(12):3597-3605. [PubMed: 18052969]

242. Bosch OJ. Maternal nurturing is dependent on her innate anxiety: the behavioral roles of brain oxytocin and vasopressin. Hormones and behavior. 2011; 59(2):202-212. [PubMed: 21094649]

243. Frankova S, Mikulecka A. Ontogeny of social behavior of pups of laboratory rats genetically selected for activity level. Activitas Nervosa Superior (Praha). 1990; 32(3):167-173.

244. Landgraf R, Wigger A. High vs low anxiety-related behavior rats: an animal model of extremes in trait anxiety. Behavioral Genetics. 2002; 32(5):301-314.

245. Veenema AH, Neumann ID. Neurobiological mechanisms of aggression and stress coping: a comparative study in mouse and rat selection lines. Brain Behav Evol. 2007; 70(4):274-285. [PubMed: 17914259]

246. Flagel SB, et al. Antecedents and consequences of drug abuse in rats selectively bred for high and low response to novelty. Neuropharmacology. 2014; 76(Pt B):425-436. [PubMed: 23639434]

247. Kabbaj M, et al. Neurobiological correlates of individual differences in novelty-seeking behavior in the rat: differential expression of stress-related molecules. Journal of Neuroscience. 2000; 20(18):6983-6988. [PubMed: 10995843]

248. Piazza PV, et al. Corticosterone in the range of stress-induced levels possesses reinforcing properties: implications for sensation-seeking behaviors. Proceedings of the National Academy of Science of the USA. 1993; 90(24):11738-11742.

249. Marquez C, Nadal R, Armario A. Influence of reactivity to novelty and anxiety on hypothalamicpituitary-adrenal and prolactin responses to two different novel environments in adult male rats. Behav Brain Res. 2006; 168(1):13-22. [PubMed: 16303185]

250. White DA, Kalinichev M, Holtzman SG. Locomotor response to novelty as a predictor of reactivity to aversive stimuli in the rat. Brain Research. 2007; 1149:141-148. [PubMed: 17383617]

251. Jama A, et al. Inter-individual differences in novelty-seeking behavior in rats predict differential responses to desipramine in the forced swim test. Psychopharmacology (Berl). 2008

252. Blanchard MM, Mendelsohn D, Stamp JA. The HR/LR model: Further evidence as an animal model of sensation seeking. Neurosci Biobehav Rev. 2009; 33(7):1145-1154. [PubMed: 19497336]

253. Stead JD, et al. Selective breeding for divergence in novelty-seeking traits: heritability and enrichment in spontaneous anxiety-related behaviors. Behav Genet. 2006; 36(5):697-712. [PubMed: 16502134]

254. Garcia-Fuster MJ, et al. The melanin-concentrating hormone ( $\mathrm{MCH}$ ) system in an animal model of depression-like behavior. European neuropsychopharmacology : the journal of the European College of Neuropsychopharmacology. 2011

255. Stedenfeld KA, et al. Novelty-seeking behavior predicts vulnerability in a rodent model of depression. Physiol Behav. 2011; 103(2):210-216. [PubMed: 21303678]

256. Clinton SM, Watson SJ, Akil H. High novelty-seeking rats are resilient to negative physiological effects of the early life stress. Stress. 2014; 17(1):97-107. [PubMed: 24090131]

257. Clements CC, et al. Prenatal antidepressant exposure is associated with risk for attention-deficit hyperactivity disorder but not autism spectrum disorder in a large health system. Mol Psychiatry. 2015; 20(6):727-734. [PubMed: 25155880]

258. Darling RD, et al. Perinatal citalopram exposure selectively increases locus ceruleus circuit function in male rats. J Neurosci. 2011; 31(46):16709-16715. [PubMed: 22090498]

259. Zhang $\mathrm{J}$, et al. Altered expression of tyrosine hydroxylase in the locus coeruleus noradrenergic system in citalopram neonatally exposed rats and monoamine oxidase a knock out mice. Anat Rec (Hoboken). 2011; 294(10):1685-1697. [PubMed: 21901841] 
260. Bourke $\mathrm{CH}$, et al. Prenatal exposure to escitalopram and/or stress in rats produces limited effects on endocrine, behavioral, or gene expression measures in adult male rats. Neurotoxicol Teratol. 2013; 39:100-109. [PubMed: 23906943]

261. Squire LR. Memory and the hippocampus: a synthesis from findings with rats, monkeys, and humans. Psychol Rev. 1992; 99(2):195-231. [PubMed: 1594723]

262. Eichenbaum H, Otto T, Cohen NJ. The hippocampus--what does it do? Behav Neural Biol. 1992; 57(1):2-36. [PubMed: 1567331]

263. Ergorul C, Eichenbaum H. The hippocampus and memory for "what," "where," and "when". Learn Mem. 2004; 11(4):397-405. [PubMed: 15254219]

264. Fortin NJ, Agster KL, Eichenbaum HB. Critical role of the hippocampus in memory for sequences of events. Nat Neurosci. 2002; 5(5):458-462. [PubMed: 11976705]

265. Shapiro ML, Eichenbaum H. Hippocampus as a memory map: synaptic plasticity and memory encoding by hippocampal neurons. Hippocampus. 1999; 9(4):365-384. [PubMed: 10495019]

266. Sapolsky RM, Krey LC, McEwen BS. Glucocorticoid-sensitive hippocampal neurons are involved in terminating the adrenocortical stress response. Proceedings of the National Academy of Sciences of the U S A. 1984; 81(19):6174-6177.

267. Jacobson L, Sapolsky R. The role of the hippocampus in feedback regulation of the hypothalamic-pituitary-adrenocortical axis. Endocr Rev. 1991; 12(2):118-134. [PubMed: 2070776]

268. Belzung C. Hippocampal mossy fibres: implication in novelty reactions or in anxiety behaviours? Behav Brain Res. 1992; 51(2):149-155. [PubMed: 1466781]

269. Lever C, Burton S, O'Keefe J. Rearing on hind legs, environmental novelty, and the hippocampal formation. Rev Neurosci. 2006; 17(1-2):111-133. [PubMed: 16703946]

270. Jeewajee A, et al. Environmental novelty is signaled by reduction of the hippocampal theta frequency. Hippocampus. 2008; 18(4):340-348. [PubMed: 18081172]

271. Bannerman DM, et al. Ventral hippocampal lesions affect anxiety but not spatial learning. Behav Brain Res. 2003; 139(1-2):197-213. [PubMed: 12642189]

272. Engin E, Treit D. The role of hippocampus in anxiety: intracerebral infusion studies. Behav Pharmacol. 2007; 18(5-6):365-374. [PubMed: 17762507]

273. Gray, JA. The neuropsychology of anxiety: An enquiry into the functions of the septohippocampal system. Oxford, UK: Oxford University Press; 1982.

274. McNaughton N, Gray JA. Anxiolytic action on the behavioural inhibition system implies multiple types of arousal contribute to anxiety. J Affect Disord. 2000; 61(3):161-176. [PubMed: 11163419]

275. McEwen BS, Gould EA, Sakai RR. The vulnerability of the hippocampus to protective and destructive effects of glucocorticoids in relation to stress. Br J Psychiatry Suppl. 1992; (15):1823. [PubMed: 1389022]

276. Witter, MP. A survey of the anatomy of the hippocampal formation, with emphasis on the septotemporal organization of its intrinsic and extrinsic connections. In: Schwarcz, R.; Ben-Ari, Y., editors. Excitatory amino acides and epilepsy (Advances in Experimental and Medical Biology. New York: Plenum Press; 1986. p. 67-82.

277. Siegel A, Tassoni JP. Differential efferent projections from the ventral and dorsal hippocampus of the cat. Brain Behav Evol. 1971; 4(3):185-200. [PubMed: 4940677]

278. Swanson LW, Cowan WM. An autoradiographic study of the organization of the efferent connections of the hippocampal formation in the rat. J Comp Neurol. 1977; 172(1):49-84. [PubMed: 65364]

279. Jay TM, Witter MP. Distribution of hippocampal CA1 and subicular efferents in the prefrontal cortex of the rat studied by means of anterograde transport of Phaseolus vulgaris-leucoagglutinin. J Comp Neurol. 1991; 313(4):574-586. [PubMed: 1783682]

280. Verwer RW, et al. Collateral projections from the rat hippocampal formation to the lateral and medial prefrontal cortex. Hippocampus. 1997; 7(4):397-402. [PubMed: 9287079]

281. Petrovich GD, Canteras NS, Swanson LW. Combinatorial amygdalar inputs to hippocampal domains and hypothalamic behavior systems. Brain Res Brain Res Rev. 2001; 38(1-2):247-289. [PubMed: 11750934] 
282. Pitkanen A, et al. Reciprocal connections between the amygdala and the hippocampal formation, perirhinal cortex, and postrhinal cortex in rat. A review. Ann N Y Acad Sci. 2000; 911:369-391. [PubMed: 10911886]

283. Krettek JE, Price JL. Projections from the amygdaloid complex and adjacent olfactory structures to the entorhinal cortex and to the subiculum in the rat and cat. J Comp Neurol. 1977; 172(4): 723-752. [PubMed: 838896]

284. O'Leary OF, Cryan JF. A ventral view on antidepressant action: roles for adult hippocampal neurogenesis along the dorsoventral axis. Trends Pharmacol Sci. 2014; 35(12):675-687. [PubMed: 25455365]

285. Moser MB, Moser EI. Functional differentiation in the hippocampus. Hippocampus. 1998; 8(6): 608-619. [PubMed: 9882018]

286. Bannerman DM, et al. Regional dissociations within the hippocampus--memory and anxiety. Neurosci Biobehav Rev. 2004; 28(3):273-283. [PubMed: 15225971]

287. Bannerman DM, et al. Double dissociation of function within the hippocampus: spatial memory and hyponeophagia. Behav Neurosci. 2002; 116(5):884-901. [PubMed: 12369808]

288. Bertoglio LJ, Joca SR, Guimaraes FS. Further evidence that anxiety and memory are regionally dissociated within the hippocampus. Behav Brain Res. 2006; 175(1):183-188. [PubMed: 16996146]

289. Gray JA, McNaughton N. The neuropsychology of anxiety: reprise. Nebr Symp Motiv. 1996; 43:61-134. [PubMed: 8912308]

290. McNaughton N. Cognitive dysfunction resulting from hippocampal hyperactivity--a possible cause of anxiety disorder? Pharmacol Biochem Behav. 1997; 56(4):603-611. [PubMed: 9130284]

291. Ely DL, Greene EG, Henry JP. Effects of hippocampal lesion on cardiovascular, adrenocortical and behavioral response patterns in mice. Physiol Behav. 1977; 18(6):1075-1083. [PubMed: 928530]

292. Kolb B, Nonneman AJ. Frontolimbic lesions and social behavior in the rat. Physiol Behav. 1974; 13(5):637-643. [PubMed: 4610602]

293. Maaswinkel $\mathrm{H}$, et al. Roles of the basolateral amygdala and hippocampus in social recognition in rats. Physiol Behav. 1996; 60(1):55-63. [PubMed: 8804643]

294. Maaswinkel H, Gispen WH, Spruijt BM. Executive function of the hippocampus in social behavior in the rat. Behav Neurosci. 1997; 111(4):777-784. [PubMed: 9267654]

295. Michal EK. Effects of limbic lesions on behavior sequences and courtship behavior of male rats (Rattus norvegicus). Behaviour. 1973; 44(3):264-285. [PubMed: 4711461]

296. Stevenson EL, Caldwell HK. Lesions to the CA2 region of the hippocampus impair social memory in mice. Eur J Neurosci. 2014; 40(9):3294-3301. [PubMed: 25131412]

297. Hitti FL, Siegelbaum SA. The hippocampal CA2 region is essential for social memory. Nature. 2014; 508(7494):88-92. [PubMed: 24572357]

298. Felix-Ortiz AC, Tye KM. Amygdala inputs to the ventral hippocampus bidirectionally modulate social behavior. J Neurosci. 2014; 34(2):586-595. [PubMed: 24403157]

299. Zou D, et al. DREADD in parvalbumin interneurons of the dentate gyrus modulates anxiety, social interaction and memory extinction. Curr Mol Med. 2016; 16(1):91-102. [PubMed: 26733123]

300. West AP. Neurobehavioral studies of forced swimming: the role of learning and memory in the forced swim test. Prog Neuropsychopharmacol Biol Psychiatry. 1990; 14(6):863-877. [PubMed: 2277851]

301. Carreno FR, et al. Activation of a ventral hippocampus-medial prefrontal cortex pathway is both necessary and sufficient for an antidepressant response to ketamine. Mol Psychiatry. 2015

302. Hannon J, Hoyer D. Molecular biology of 5-HT receptors. Behav Brain Res. 2008; 195(1):198213. [PubMed: 18571247]

303. Xu T, Pandey SC. , Cellular localization of serotonin(2A) (5HT(2A)) receptors in the rat brain. Brain Res Bull. 2000; 51(6):499-505. [PubMed: 10758340] 
304. Tecott LH, Maricq AV, Julius D. Nervous system distribution of the serotonin 5-HT3 receptor mRNA. Proc Natl Acad Sci U S A. 1993; 90(4):1430-1434. [PubMed: 8434003]

305. Vilaro MT, et al. Localization of 5-HT4 receptor mRNA in rat brain by in situ hybridization histochemistry. Brain Res Mol Brain Res. 1996; 43(1-2):356-360. [PubMed: 9037555]

306. Carson MJ, et al. The 5HT5A serotonin receptor is expressed predominantly by astrocytes in which it inhibits cAMP accumulation: a mechanism for neuronal suppression of reactive astrocytes. Glia. 1996; 17(4):317-326. [PubMed: 8856328]

307. Kinsey AM, et al. Distribution of 5-ht(5A), 5-ht(5B), 5-ht(6) and 5-HT(7) receptor mRNAs in the rat brain. Brain Res Mol Brain Res. 2001; 88(1-2):194-198. [PubMed: 11295248]

308. Ruat M, et al. Molecular cloning, characterization, and localization of a high-affinity serotonin receptor (5-HT7) activating cAMP formation. Proc Natl Acad Sci U S A. 1993; 90(18):85478551. [PubMed: 8397408]

309. Johnston A, McBain CJ, Fisahn A. 5-Hydroxytryptamine1A receptor-activation hyperpolarizes pyramidal cells and suppresses hippocampal gamma oscillations via Kir3 channel activation. J Physiol. 2014; 592(Pt 19):4187-4199. [PubMed: 25107925]

310. Colgin LL, Moser EI. Gamma oscillations in the hippocampus. Physiology (Bethesda). 2010; 25(5):319-329. [PubMed: 20940437]

311. Johnston A, McBain CJ, Fisahn A. 5-Hydroxytryptamine1A receptor-activation hyperpolarizes pyramidal cells and suppresses hippocampal gamma oscillations via Kir3 channel activation. J Physiol. 2014; 592(19):4187-4199. [PubMed: 25107925]

312. Azmitia EC, et al. Cellular localization of the 5-HT1A receptor in primate brain neurons and glial cells. Neuropsychopharmacology. 1996; 14(1):35-46. [PubMed: 8719028]

313. Alenina N, Klempin F. The role of serotonin in adult hippocampal neurogenesis. Behav Brain Res. 2015; 277:49-57. [PubMed: 25125239]

314. Saudou F, Hen R. 5-Hydroxytryptamine receptor subtypes: molecular and functional diversity. Adv Pharmacol. 1994; 30:327-380. [PubMed: 7833295]

315. Mlinar B, Falsini C, Corradetti R. Pharmacological characterization of 5-HT(1B) receptormediated inhibition of local excitatory synaptic transmission in the CA1 region of rat hippocampus. Br J Pharmacol. 2003; 138(1):71-80. [PubMed: 12522075]

316. Passani MB, et al. Effects of DAU 6215, a novel 5-hydroxytryptamine3 (5-HT3) antagonist on electrophysiological properties of the rat hippocampus. Br J Pharmacol. 1994; 112(2):695-703. [PubMed: 8075890]

317. Fink KB, Gothert M. 5-HT receptor regulation of neurotransmitter release. Pharmacol Rev. 2007; 59(4):360-417. [PubMed: 18160701]

318. Djavadian RL. Serotonin and neurogenesis in the hippocampal dentate gyrus of adult mammals. Acta Neurobiol Exp (Wars). 2004; 64(2):189-200. [PubMed: 15366252]

319. Tokarski K, Kusek M, Hess G. 5-HT7 receptors modulate GABAergic transmission in rat hippocampal CA1 area. J Physiol Pharmacol. 2011; 62(5):535-540. [PubMed: 22204801]

320. West PJ, et al. Activation of the 5-HT(6) receptor attenuates long-term potentiation and facilitates GABAergic neurotransmission in rat hippocampus. Neuroscience. 2009; 164(2):692-701. [PubMed: 19660530]

321. Costa L, et al. 5-HT(1A) and 5-HT(7) receptors differently modulate AMPA receptor-mediated hippocampal synaptic transmission. Hippocampus. 2012; 22(4):790-801. [PubMed: 21538661]

322. Liu H, et al. Acute tryptophan depletion reduces nitric oxide synthase in the rat hippocampus. Neurochem Res. 2013; 38(12):2595-2603. [PubMed: 24170240]

323. Vataeva LA, et al. Behavioral alteration in the adult rats prenatally exposed to parachlorophenylalanine. Brain Res. 2007; 1169:9-16. [PubMed: 17698045]

324. Paxinos, G. The rat nervous system. Sydney ; Orlando: Academic Press; 1985.

325. Ming GL, Song H. Adult neurogenesis in the mammalian central nervous system. Annu Rev Neurosci. 2005; 28:223-250. [PubMed: 16022595]

326. Mahar I, et al. Stress, serotonin, and hippocampal neurogenesis in relation to depression and antidepressant effects. Neurosci Biobehav Rev. 2014; 38:173-192. [PubMed: 24300695] 
327. Hill AS, Sahay A, Hen R. Increasing Adult Hippocampal Neurogenesis is Sufficient to Reduce Anxiety and Depression-Like Behaviors. Neuropsychopharmacology. 2015; 40(10):2368-2378. [PubMed: 25833129]

328. David DJ, et al. Neurogenesis-dependent and -independent effects of fluoxetine in an animal model of anxiety/depression. Neuron. 2009; 62(4):479-493. [PubMed: 19477151]

329. Holick KA, et al. Behavioral effects of chronic fluoxetine in BALB/cJ mice do not require adult hippocampal neurogenesis or the serotonin 1A receptor. Neuropsychopharmacology. 2008; 33(2): 406-417. [PubMed: 17429410]

330. Sahay A, et al. Increasing adult hippocampal neurogenesis is sufficient to improve pattern separation. Nature. 2011; 472(7344):466-470. [PubMed: 21460835]

331. McEwen BS. Early life influences on life-long patterns of behavior and health. Ment Retard Dev Disabil Res Rev. 2003; 9(3):149-154. [PubMed: 12953293]

332. Pechtel P, Pizzagalli DA. Effects of early life stress on cognitive and affective function: an integrated review of human literature. Psychopharmacology (Berl). 2011; 214(1):55-70. [PubMed: 20865251]

333. Sanchez MM, Ladd CO, Plotsky PM. Early adverse experience as a developmental risk factor for later psychopathology: evidence from rodent and primate models. Developmental Psychopathology. 2001; 13(3):419-449.

334. Menke A, Klengel T, Binder EB. Epigenetics, depression and antidepressant treatment. Curr Pharm Des. 2012; 18(36):5879-5889. [PubMed: 22681167]

335. Vialou V, et al. Epigenetic mechanisms of depression and antidepressant action. Annu Rev Pharmacol Toxicol. 2013; 53:59-87. [PubMed: 23020296]

336. Melas PA, et al. Antidepressant treatment is associated with epigenetic alterations in the promoter of P11 in a genetic model of depression. Int J Neuropsychopharmacol. 2012; 15(5):669-679. [PubMed: 21682946]

337. Zimmermann N, et al. Antidepressants inhibit DNA methyltransferase 1 through reducing G9a levels. Biochem J. 2012; 448(1):93-102. [PubMed: 22880885]

338. Cassel S, et al. Fluoxetine and cocaine induce the epigenetic factors MeCP2 and MBD1 in adult rat brain. Mol Pharmacol. 2006; 70(2):487-492. [PubMed: 16670375]

339. Sales AJ, et al. Antidepressant-like effect induced by systemic and intra-hippocampal administration of DNA methylation inhibitors. British journal of pharmacology. 2011; 164(6): 1711-1721. [PubMed: 21585346]

340. Tsankova NM, et al. Sustained hippocampal chromatin regulation in a mouse model of depression and antidepressant action. Nat Neurosci. 2006; 9(4):519-525. [PubMed: 16501568]

341. Benton CS, et al. Evaluating genetic markers and neurobiochemical analytes for fluoxetine response using a panel of mouse inbred strains. Psychopharmacology (Berl). 2012; 221(2):297315. [PubMed: 22113448]

342. Schroeder FA, et al. Antidepressant-like effects of the histone deacetylase inhibitor, sodium butyrate, in the mouse. Biol Psychiatry. 2007; 62(1):55-64. [PubMed: 16945350]

343. Yamawaki Y, et al. Antidepressant-like effect of sodium butyrate (HDAC inhibitor) and its molecular mechanism of action in the rat hippocampus. World J Biol Psychiatry. 2012; 13(6): 458-467. [PubMed: 21812623]

344. Covington HE 3rd, et al. Antidepressant actions of histone deacetylase inhibitors. J Neurosci. 2009; 29(37):11451-11460. [PubMed: 19759294]

345. Non AL, et al. Genome-wide DNA methylation in neonates exposed to maternal depression, anxiety, or SSRI medication during pregnancy. Epigenetics. 2014; 9(7):964-972. [PubMed: 24751725]

346. Glover, ME., et al. Society for Neuroscience Abstracts. Chicago, IL: 2015. Early-life exposure to the SSRI paroxetine disrupts DNA methylation in the early postnatal hippocampus.

347. Homberg JR, Schubert D, Gaspar P. New perspectives on the neurodevelopmental effects of SSRIs. Trends Pharmacol Sci. 2010; 31(2):60-65. [PubMed: 19963284]

348. Oberlander TF. Fetal serotonin signaling: setting pathways for early childhood development and behavior. J Adolesc Health. 2012; 51(2 Suppl):S9-S16. [PubMed: 22794534] 
349. Wilkinson LS, Davies W, Isles AR. Genomic imprinting effects on brain development and function. Nat Rev Neurosci. 2007; 8(11):832-843. [PubMed: 17925812]

350. Luedi PP, Hartemink AJ, Jirtle RL. Genome-wide prediction of imprinted murine genes. Genome Res. 2005; 15(6):875-884. [PubMed: 15930497]

351. Rayen I, et al. Developmental exposure to SSRIs, in addition to maternal stress, has long-term sex-dependent effects on hippocampal plasticity. Psychopharmacology (Berl). 2015; 232(7): 1231-1244. [PubMed: 25304865] 


\section{Highlights}

- $\quad$ Children exposed to SSRI antidepressants in early life display changes in affective behavior, such as increased anxiety and depression-like behaviors and increased risk for autism. This review summarizes the known effects of early life SSRI exposure in humans and rodents and highlights molecular mechanisms that may mediate its deleterious effects on brain and behavior.

- $\quad$ Rodent studies indicate that early life SSRI exposure impairs normal brain development, with long lasting changes observed in 5-HTergic tone, hippocampal neurogenesis, and epigenetic programming.

- $\quad$ Emerging evidence suggests that certain children may be at greater risk for developing mood disorders following early life antidepressant drug exposure, although the biological underpinnings of this effect are unknown.

- $\quad$ Such findings are important for developing individualized treatment strategies for depressed women who are or plan to become pregnant. 


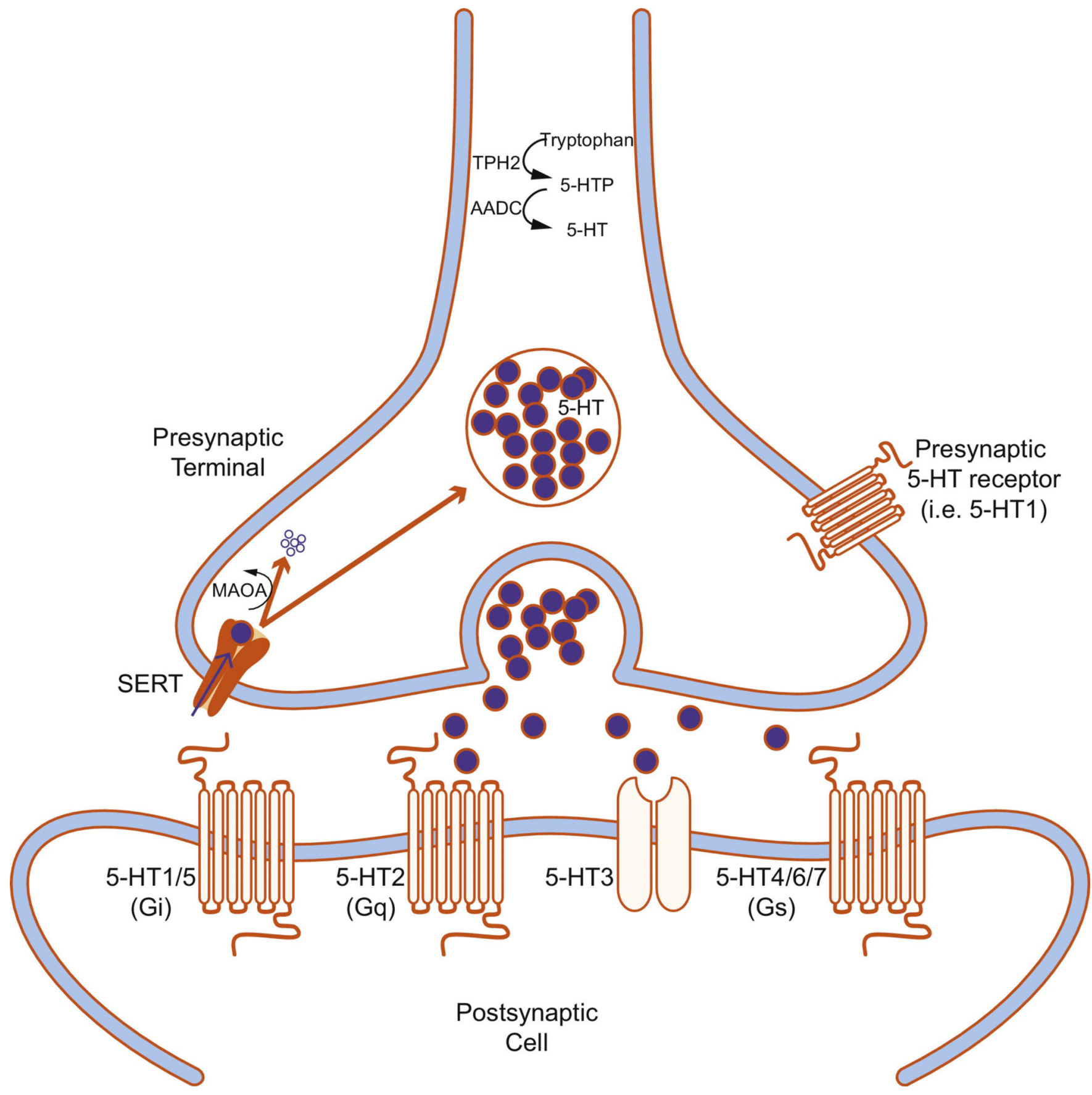

Figure 1.

Schematic of a serotonergic synapse. Serotonin (5-hydroxytryptamine, 5-HT) is synthesized when tryptophan hydroxylase 2 (TPH2) converts tryptophan to 5-hydroxytryptophan (5HTP), which is converted to 5-HT by aromatic L-amino acid decarboxylase (AADC). 5-HT is stored in synaptic vesicles in the presynaptic terminal until an action potential triggers its release into the synaptic cleft where it can activate a variety of postsynaptic receptors (5HT1-7). One type of 5-HT receptor (5-HT3) is a ligand-gated ion channel, but the rest are G protein-coupled receptors. 5-HT1 and 5-HT5 are Gi/Go-protein coupled receptors that 
decrease cellular levels of cyclicAMP (cAMP). 5-HT2 is a Gq/G11-protein coupled receptor that increases cellular levels of inositol trisphosphate and diacylglycerol. 5-HT4, 5-HT6, and 5-HT7 are Gs-protein coupled receptors that increase cellular levels of cAMP. 5-HT can also bind to presynaptic receptors to regulate activity of the presynaptic neuron. 5-HTergic action is terminated when it is removed from the synapse via the 5-HT reuptake transporter (SERT) located on the presynaptic neuron. At that point, 5-HT can either be recycled for future release, or catabolyzed by monoamine oxidase (MAO). 


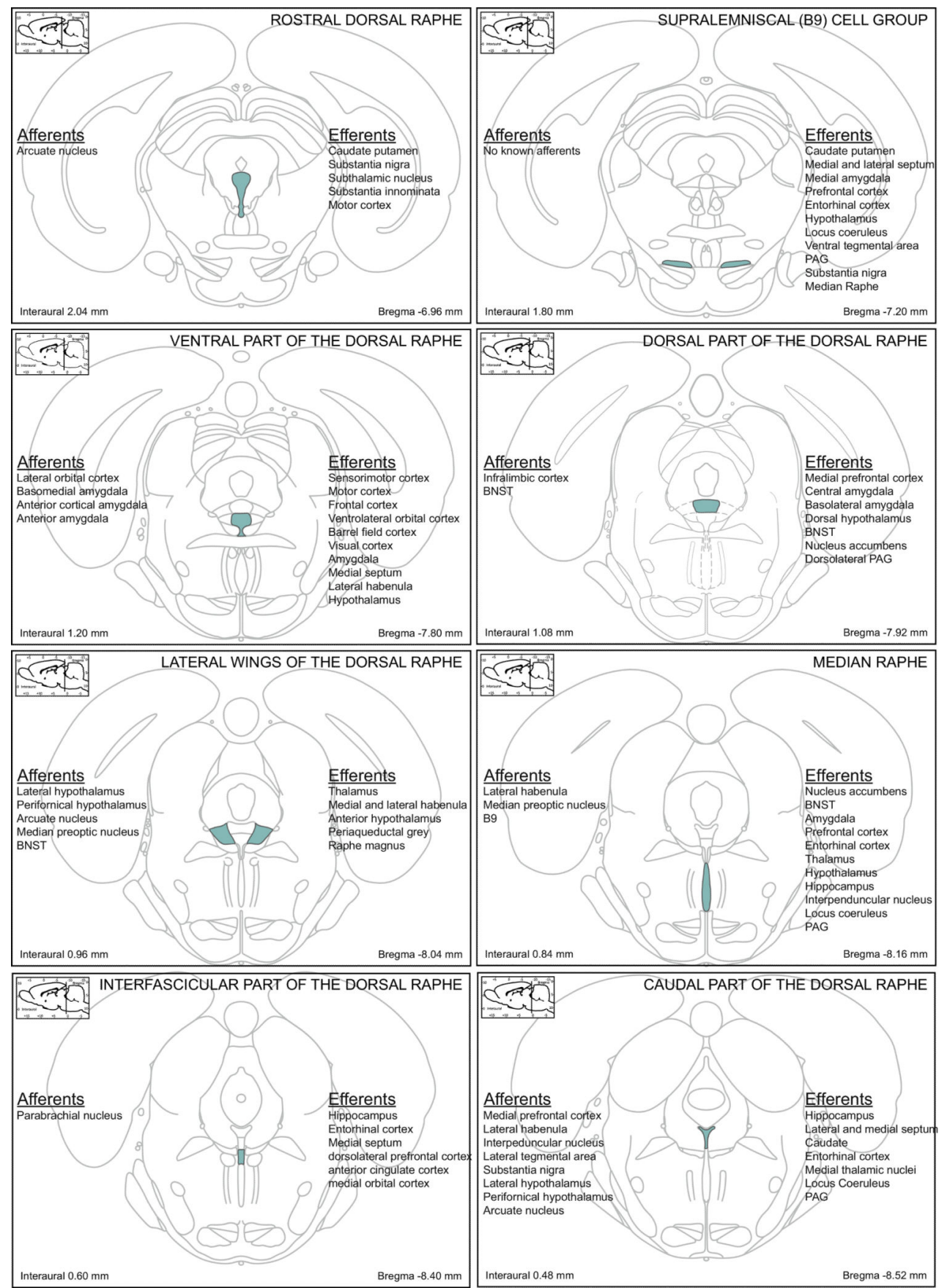

Figure 2.

Summary of afferent/efferent projections of major raphe nuclei. 


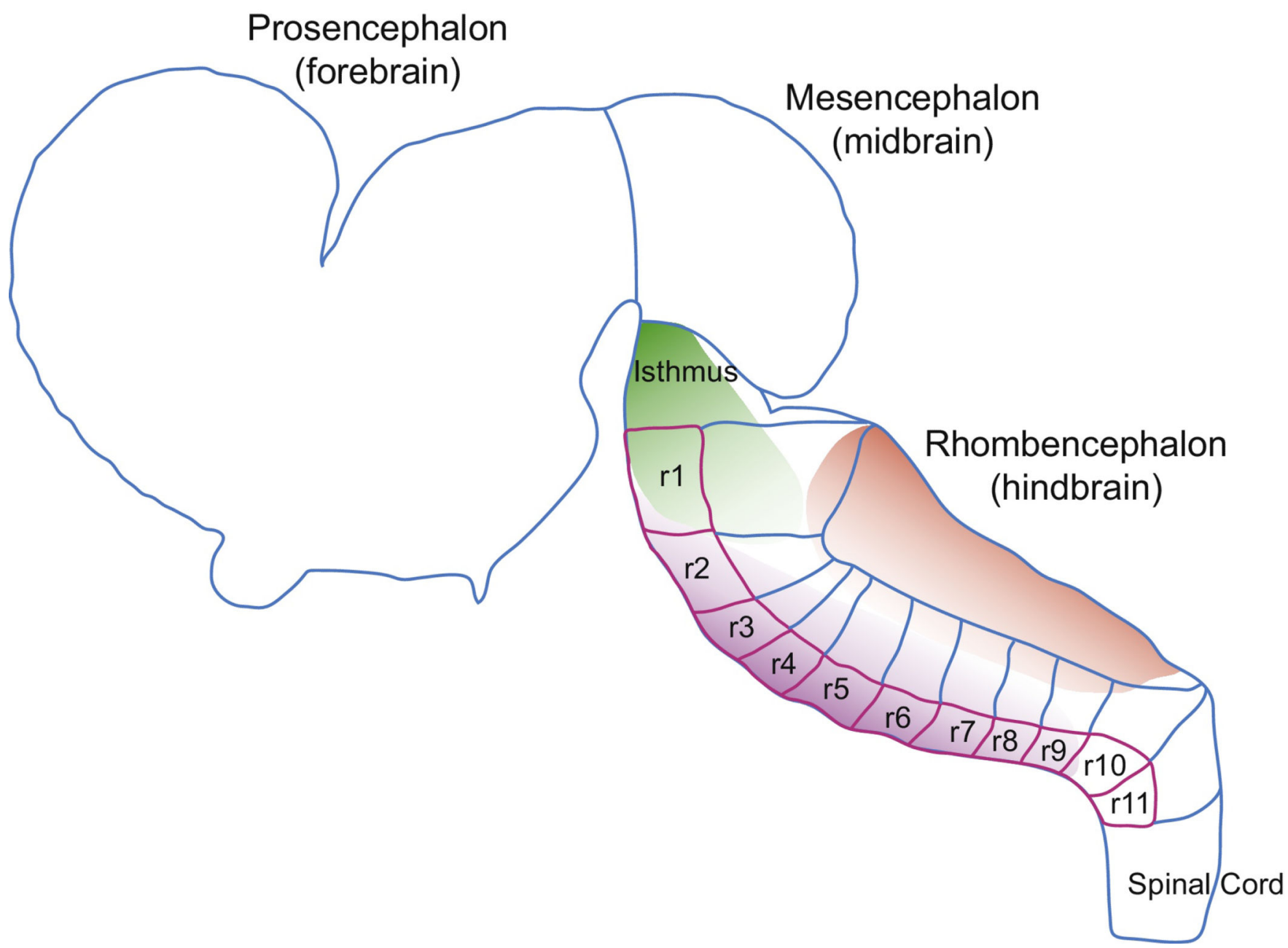

Figure 3.

Diagram of a lateral view of the developing rat brain. The developing mammalian brain is comprised of three major elements: the forebrain (prosencephalon), midbrain (mesencephalon), and hindbrain (rhombencephalon). Serotonin-producing neurons of the raphe will form in the hindbrain within a subset of its 12 neuromeric units, the isthmus through rhombomere (r) 1 to r11. Morphpgen gradients induce transcription factor cascades leading to 5-HT neuron differentiation. FGF4 is released dorsally from the primitive streak, FGF8 from the isthmus, and SonciHedgehog ventrally from the floor plate. Serotonin neuron progenitors derived from specific rhombomeres eventually mature into functionallyand anatomically-distinct nuclei. For instance, while serotonin progenitor cells are located in r1-3 and r5-7, cells originating in r1 later form nuclei B7, B6 and B4, while r1- and r2derived serotonin neurons contribute to formation of B9, B8 and B5 nuclei. Figure 3. Diagram of a lateral view of the developing rat brain. The developing mammalian brain is comprised of three major elements: the forebrain (prosencephalon), midbrain (mesencephalon), and hindbrain (rhombencephalon). Serotonin-producing neurons of the raphe will form in the hindbrain within a subset of its 12 neuromeric units, the isthmus through rhombomere (r) 1 to 11 . Morphpgen gradients induce transcription factor cascades leading to 5-HT neuron differentiation. FGF4 is released dorsally from the primitive streak, 
FGF8 from the isthmus, and SonciHedgehog ventrally from the floor plate. Serotonin neuron progenitors derived from specific rhombomeres eventually mature into functionallyand anatomically-distinct nuclei. For instance, while serotonin progenitor cells are located in r1-3 and r5-7, cells originating in r1 later form nuclei B7, B6 and B4, while r1- and r2derived serotonin neurons contribute to formation of B9, B8 and B5 nuclei. 


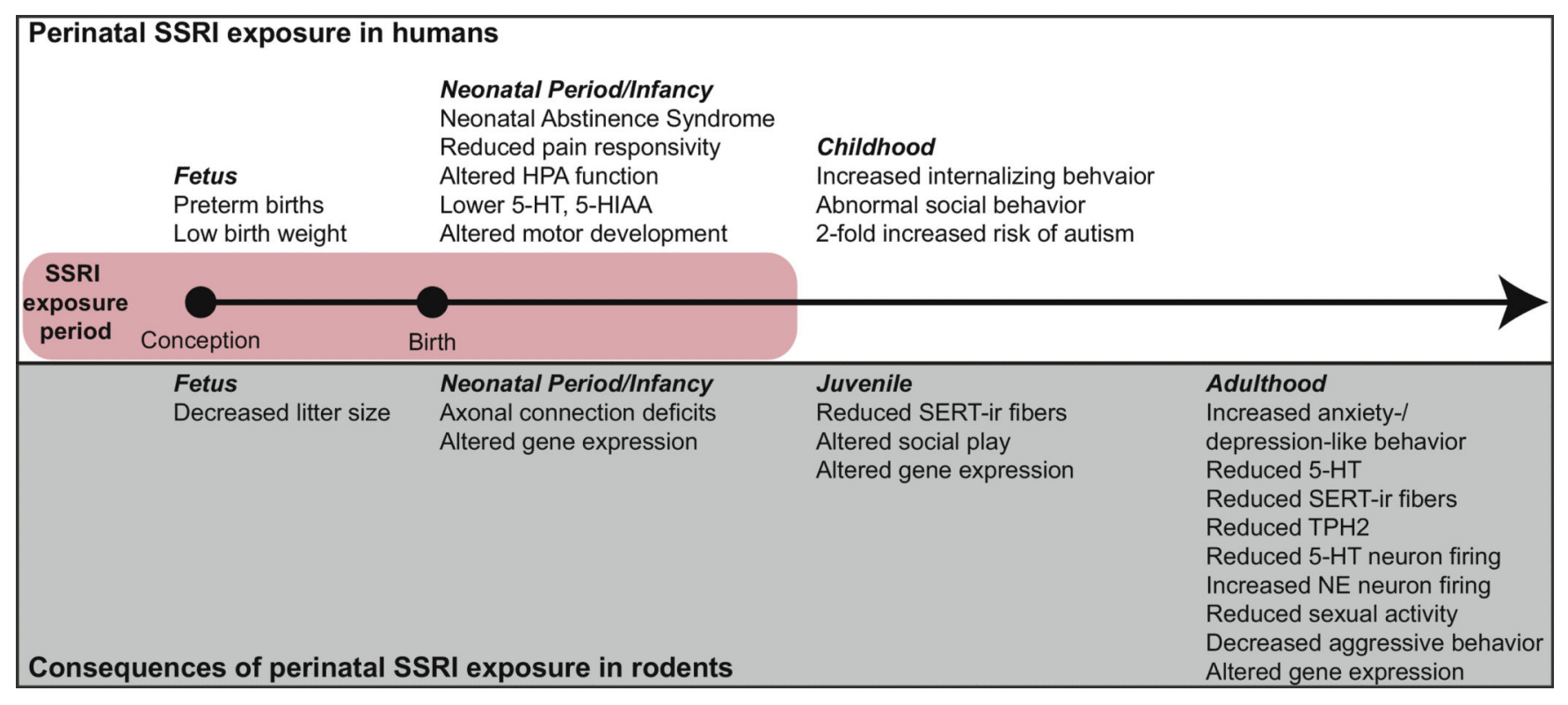

Figure 4.

Overview of physiological and behavioral effects in offspring exposed to selective serotonin reuptake inhibitor (SSRI) antidepressants during early life. The pink rectangle indicates period of time when offspring are typically exposed to SSRIs (often prenattaly through the postnatal lactation period, since depressed women are frequently treated with SSRIs throughout pregnancy and the postpartum period). The top box highlights effects reported in children exposed to SSRIs in early life. Importantly, none of the work in humans to-date has examined effects beyond childhood, so the long-term consequences of early-life SSRI exposure on human behavior remain unknown. The bottom box in gray highlights a number of rodent studies showing that perinatal SSRI exposure causes life-long adverse outcomes, including increases in anxiety- and depression-like behavior. 


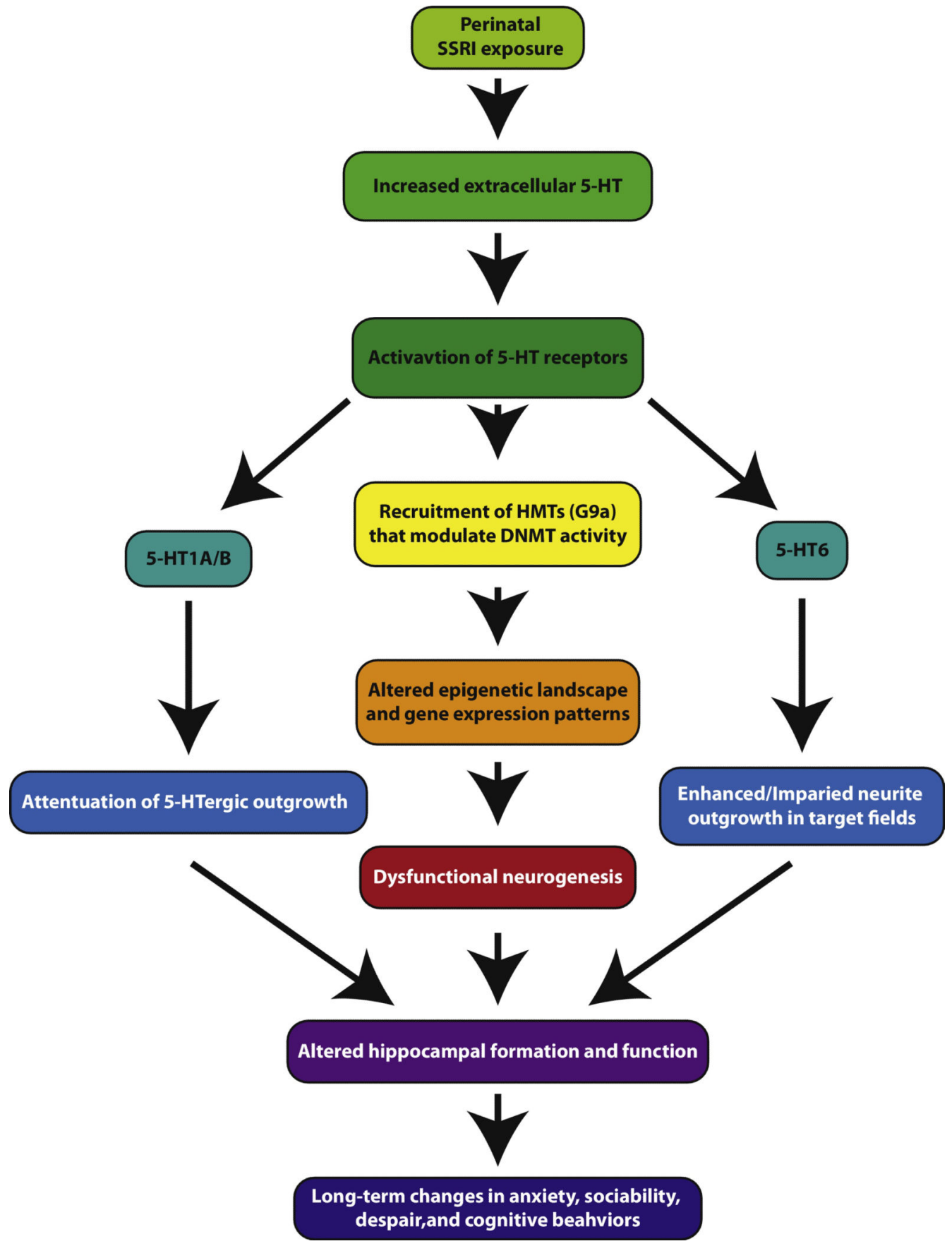

Figure 5.

Concept map summarizing the effects of perinatal SSRI exposure on neurodevelopment. Blockade of serotonin (5-hydroxytryptamine, 5-HT) reuptake from the synaptic cleft (selective 5-HT reuptake inhibitors [SSRIs'] main mode of action) leads to increased synaptic 5-HT levels and increased activation of 5-HT receptors. 5-HT1 and 5-HT6 receptors serve as examples in this diagram. Increased 5-HT1 receptor activation triggers long-term attenuation of 5-HTergic fiber outgrowth, while increased 5-HT6 activity leads to enhanced neurite outgrowth in some target fields. Increased 5-HT receptor activation in the 
hippocampus may modulate of enzymes involved in epigenetic processes, such as histone methyltransferase (HMT) G9a and DNA methyltransferases (DNMTs). Modulation of these epigenetic enzymes could elicit downstream changes in the epigenome and subsequent gene expression. Perintal SSRI-induced shifts in the hippocampal epigenome and transcriptome could, in turn, trigger a number of downstream effects, including changes in hippocampal neurogenesis, synaptogenesis, and hippocampal circuit development as well as long-lasting changes in affective, social, and cognitive behavior. 


\section{Table 1}

Nomenclature assigned to serotonin cell groups

\begin{tabular}{|c|c|}
\hline Cell Group & Cytoarchitectural region \\
\hline B1 & $\begin{array}{l}\text { Raphe pallidus nucleus }(\mathrm{RPa}) \text { and Caudal ventrolateral } \\
\text { medulla (CVL) }\end{array}$ \\
\hline $\mathrm{B} 2$ & Raphe obscurus nucleus (ROb) \\
\hline B3 & $\begin{array}{l}\text { Raphe magnus nucleus (RMg), Rostral ventrolateral } \\
\text { medulla (RVL), and Lateral paragigantocellular reticular } \\
\text { nucleus (LPGi) }\end{array}$ \\
\hline B4 & Central gray of the medulla oblongata \\
\hline B5 & Pontine median raphe nucleus (MnR) \\
\hline B6 & Pontine dorsal raphe nucleus (DR) \\
\hline B7 & Midbrain dorsal raphe nucleus (DR) \\
\hline B8 & $\begin{array}{l}\text { Midbrain median raphe nucleus (MnR) and } \\
\text { Caudal linear nucleus (CLi) }\end{array}$ \\
\hline B9 & $\begin{array}{l}\text { Supralemniscal region, Pontomesencephalic Reticular } \\
\text { Formation (PMRF) }\end{array}$ \\
\hline
\end{tabular}

Int J Dev Neurosci. Author manuscript; available in PMC 2017 June 01. 


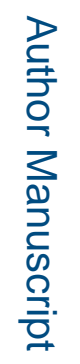

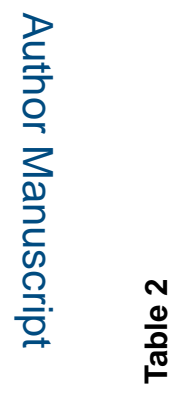

ᄅ⿱亠䒑十⺝

\begin{tabular}{|c|c|c|c|c|c|c|c|c|c|c|c|c|c|c|c|c|}
\hline 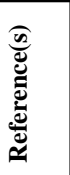 & $\underset{\widetilde{d}}{\sqrt{d}}$ & ¿্ণ & $\underset{\mathrm{d}}{\stackrel{\text { D }}{2}}$ & $\overline{\tilde{m}}$ & $\underset{\bar{a}}{\bar{d}}$ & 怘 & 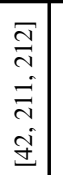 & $\stackrel{\bar{m}}{\stackrel{d}{d}}$ & ब्త్రి & $\underset{\Xi}{\Xi}$ & $\stackrel{\bar{d}}{\stackrel{\alpha}{d}}$ & $\frac{\sqrt{n}}{\sqrt{2}}$ & $\underset{\mathrm{d}}{\overrightarrow{\mathrm{d}}}$ & 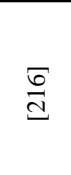 & $\begin{array}{l}\overline{\mathbb{d}} \\
\text { d }\end{array}$ & $\underset{\widetilde{\Xi}}{\widetilde{d}}$ \\
\hline 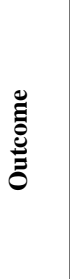 & 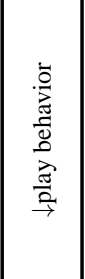 & 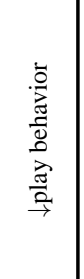 & 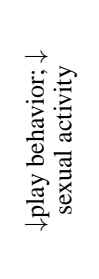 & 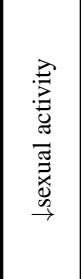 & 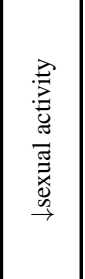 & 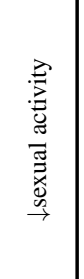 & 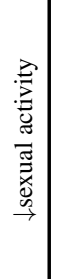 & 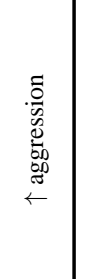 & 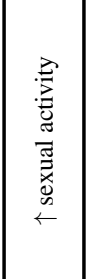 & 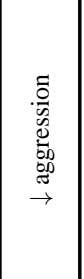 & 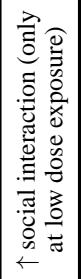 & 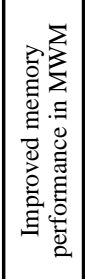 & 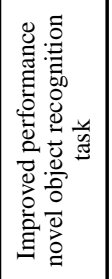 & 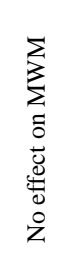 & 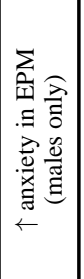 & 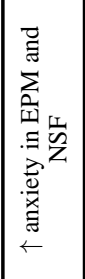 \\
\hline 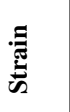 & 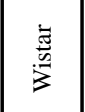 & iे & 岁 & 它 & $\begin{array}{l}\vec{p} \\
\dot{p} \\
0 \\
0\end{array}$ & 岳 & د) & $\frac{\infty}{3}$ & iे & $\begin{array}{l}\frac{\vec{g}}{5} \\
3\end{array}$ & $\frac{\vec{z}}{3}$ & $\begin{array}{l}\text { 急 } \\
3^{5}\end{array}$ & 岁 & 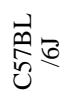 & $\frac{\vec{z}}{3}$ & $\frac{\vec{s}}{3}$ \\
\hline ڤે & 5 & ${ }^{\circ}$ & $\begin{array}{l}50 \\
\mathrm{O}^{\circ}\end{array}$ & 5 & ${ }^{\circ}$ & ${ }^{\circ}$ & 5 & 8 & $\mathrm{O}^{+}$ & 5 & 5 & $\begin{array}{l}50 \\
\mathrm{O}+\end{array}$ & $\begin{array}{l}50 \\
\mathrm{O}\end{array}$ & $\mathrm{O}+$ & $\begin{array}{l}50 \\
\mathrm{O}\end{array}$ & 5 \\
\hline 蒙 & 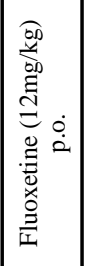 & 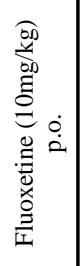 & 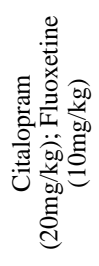 & 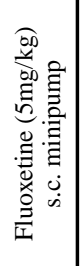 & 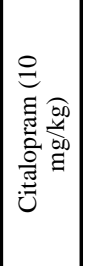 & 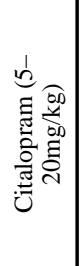 & 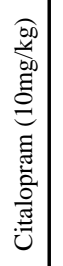 & 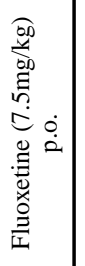 & 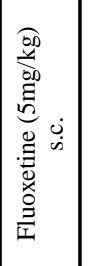 & 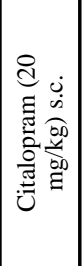 & 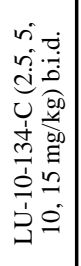 & 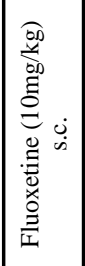 & 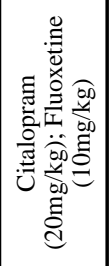 & 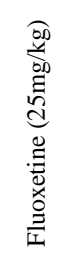 & 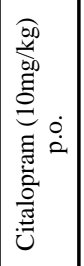 & 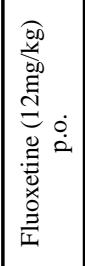 \\
\hline 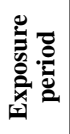 & $\frac{\stackrel{8}{1}}{\stackrel{\overrightarrow{\mid c}}{\frac{1}{2}}}$ & $\begin{array}{l}\vec{\pi} \\
\stackrel{\Omega}{\Omega}\end{array}$ & $\begin{array}{l}\vec{T} \\
\infty \\
0\end{array}$ & $\frac{\bar{T}}{\dot{a}}$ & $\begin{array}{l}\vec{T} \\
\infty \\
\infty\end{array}$ & $\begin{array}{l}\overrightarrow{\vec{T}} \\
\stackrel{\infty}{\Omega}\end{array}$ & $\begin{array}{l}\vec{T} \\
\infty \\
\alpha\end{array}$ & 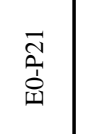 & $\frac{\tilde{1}}{2}$ & $\frac{9}{\frac{1}{2}}$ & $\begin{array}{l}\vec{r} \\
\infty \\
\stackrel{\infty}{0}\end{array}$ & $\begin{array}{l}\stackrel{T}{1} \\
\text { ஸे }\end{array}$ & $\begin{array}{l}\vec{T} \\
\infty \\
0\end{array}$ & $\frac{a}{\frac{1}{n}}$ & 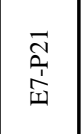 & 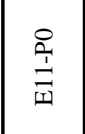 \\
\hline 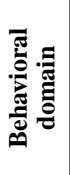 & 这 & & & & & & & & & & & & 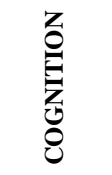 & & 窗 & \\
\hline
\end{tabular}

Int J Dev Neurosci. Author manuscript; available in PMC 2017 June 01. 


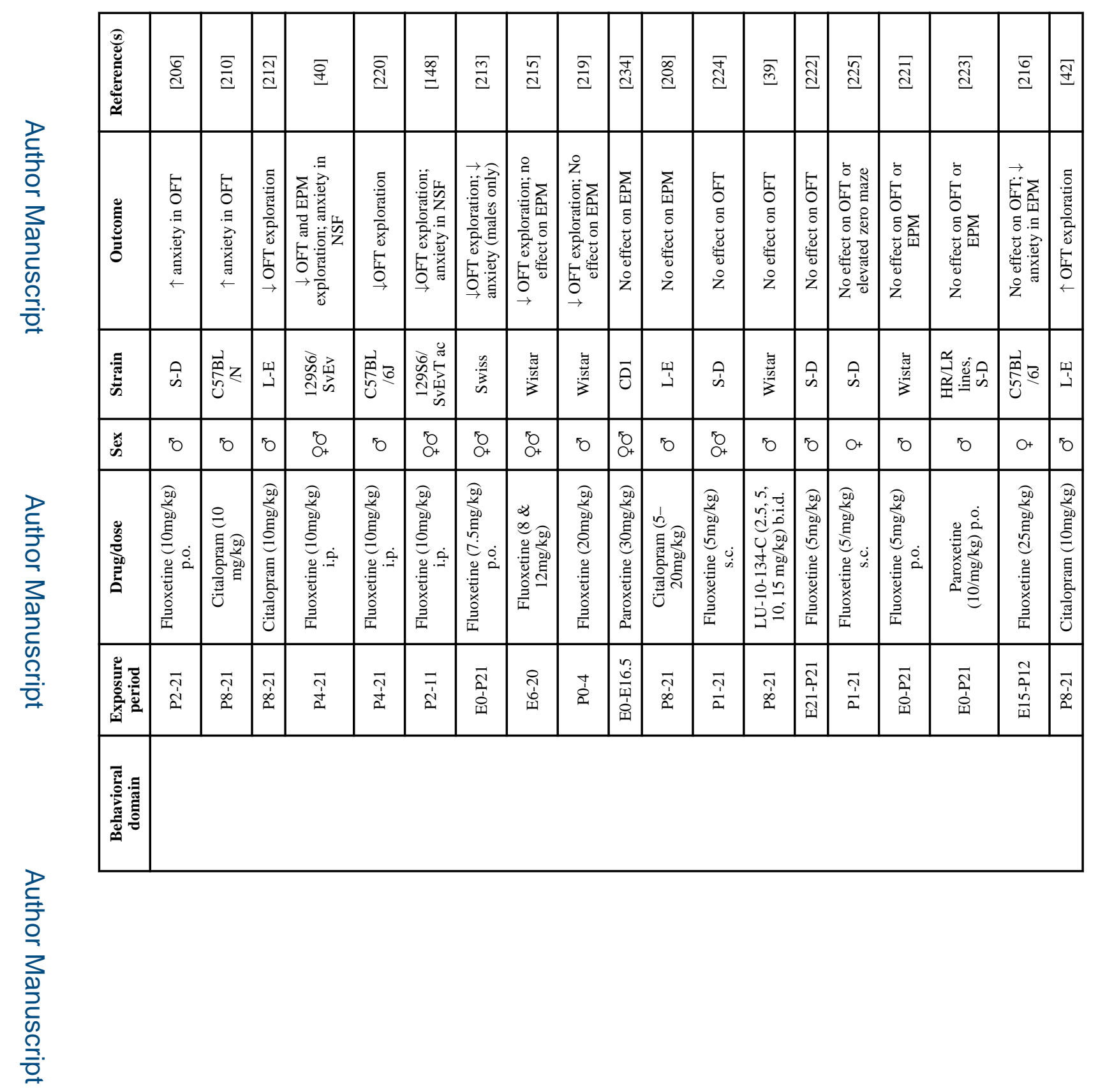

로을 


\begin{tabular}{|c|c|c|c|c|c|c|c|c|c|c|c|c|c|c|c|c|c|c|c|}
\hline 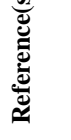 & 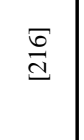 & $\begin{array}{l}\bar{d} \\
\text { d }\end{array}$ & $\begin{array}{l}\bar{\beth} \\
\text { בป }\end{array}$ & $\stackrel{\stackrel{\mathscr{\infty}}{\Xi}}{\Xi}$ & $\begin{array}{l}\bar{d} \\
\text { d }\end{array}$ & ర్ల్ల & ब్ & $\overline{\vec{\beth}}$ & $\overline{\widetilde{d}}$ & $\begin{array}{l}\overline{\widetilde{d}} \\
\widetilde{d}\end{array}$ & $\begin{array}{l}\bar{\infty} \\
\stackrel{\infty}{\infty}\end{array}$ & $\begin{array}{l}\overline{\mathbb{U}} \\
\text {. }\end{array}$ & $\frac{\bar{m}}{\underline{d}}$ & $\overline{\mathbb{d}}$ & $\begin{array}{l}\bar{D} \\
\text { d] }\end{array}$ & $\overline{\stackrel{\mathcal{d}}{\mathrm{d}}}$ & 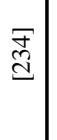 & $\begin{array}{l}\bar{్} \\
\text { d. }\end{array}$ & $\underset{\mathbb{d}}{\overline{\mathbb{d}}}$ \\
\hline 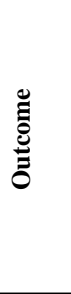 & 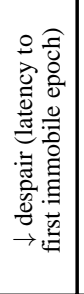 & 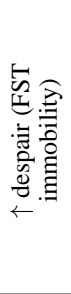 & 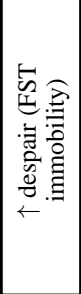 & 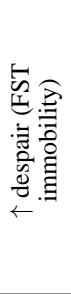 & 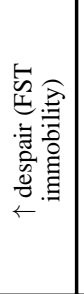 & 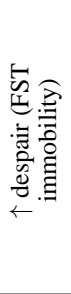 & 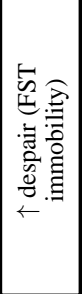 & 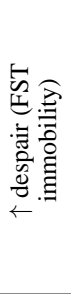 & 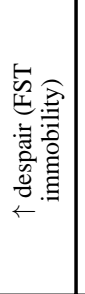 & 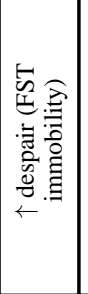 & 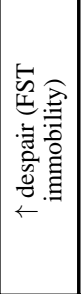 & 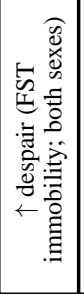 & 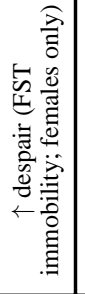 & 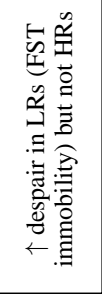 & 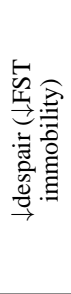 & 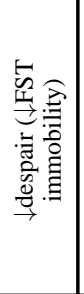 & 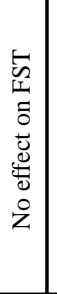 & 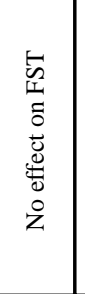 & 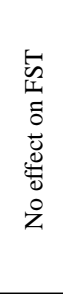 \\
\hline 嘅 & 恙 & $\begin{array}{l}\frac{\tilde{g}}{5} \\
\frac{5}{3} \\
3\end{array}$ & iे & 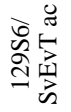 & Pि & $\begin{array}{l}\frac{\mathrm{m}}{\mathrm{m}} \\
\frac{5}{3}\end{array}$ & $\begin{array}{l}\frac{5}{5} \\
\frac{5}{3} \\
3\end{array}$ & 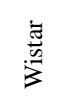 & $\frac{\tilde{\tilde{m}}}{3}$ & 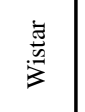 & $\frac{\vec{m}}{3}$ & $\frac{\vec{m}}{3}$ & 寗 & 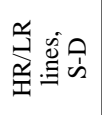 & $\begin{array}{l}\frac{\tilde{n}}{5} \\
\frac{5}{3} \\
3\end{array}$ & 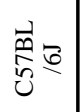 & $\overline{\mathrm{u}}$ & $\frac{5}{3}$ & ì \\
\hline ڤ్ & $\mathrm{O}_{+}$ & 5 & $\mathrm{O}^{+}$ & $\begin{array}{l}50 \\
\mathrm{O}^{+}\end{array}$ & 5 & 5 & 5 & 5 & 8 & ${ }^{\circ} 0$ & ${ }^{\circ} 0$ & $\begin{array}{l}50 \\
\mathrm{O}^{2}\end{array}$ & $\begin{array}{l}50 \\
\mathrm{O}^{2}\end{array}$ & ${ }^{\circ} 0$ & ${ }^{\circ}$ & '0 & $\begin{array}{l}50 \\
0+\end{array}$ & ${ }^{\circ} \mathrm{O}$ & $\begin{array}{l}50 \\
\mathrm{O}+\end{array}$ \\
\hline$\frac{\mathscr{D}}{0}$ & 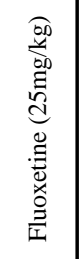 & 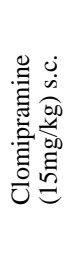 & 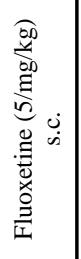 & 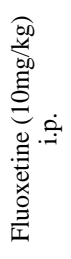 & 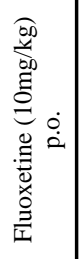 & 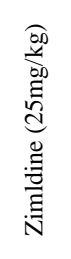 & 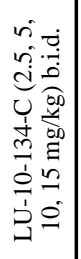 & 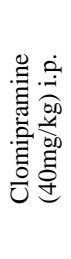 & 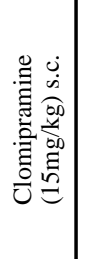 & 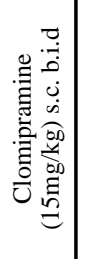 & 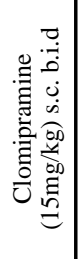 & 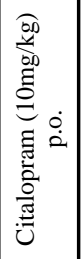 & 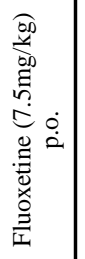 & 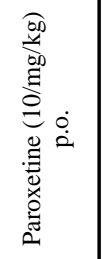 & 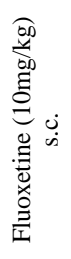 & 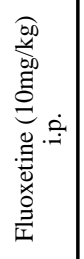 & 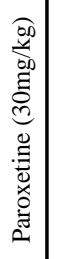 & 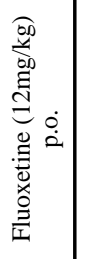 & 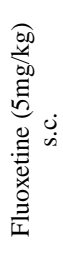 \\
\hline 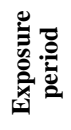 & $\begin{array}{l}\frac{a}{\Delta} \\
\frac{n}{\square}\end{array}$ & $\begin{array}{l}\overrightarrow{\widetilde{T}} \\
\stackrel{\infty}{\alpha}\end{array}$ & $\frac{\vec{T}}{\Delta}$ & $\overline{\overline{\lrcorner}}$ & $\begin{array}{l}\bar{\Omega} \\
\vec{\Omega}\end{array}$ & $\frac{\infty}{\frac{1}{2}}$ & $\begin{array}{l}\vec{T} \\
\infty \\
\alpha\end{array}$ & $\begin{array}{l}\vec{T} \\
\infty \\
a\end{array}$ & 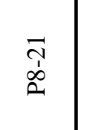 & $\begin{array}{l}\overrightarrow{\widehat{\lambda}} \\
\stackrel{\infty}{\infty}\end{array}$ & $\begin{array}{l}\vec{T} \\
\infty \\
\alpha\end{array}$ & 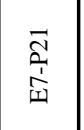 & 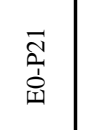 & $\begin{array}{l}\overrightarrow{\widehat{\Xi}} \\
\text { İ⿴囗十 }\end{array}$ & $\frac{\vec{T}}{\underline{a}}$ & $\begin{array}{l}\vec{T} \\
\dot{d}\end{array}$ & 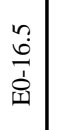 & $\stackrel{\circ}{\stackrel{0}{\pi}}$ & $\frac{\vec{I}}{\Delta}$ \\
\hline 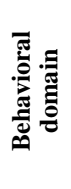 & \multicolumn{19}{|c|}{ 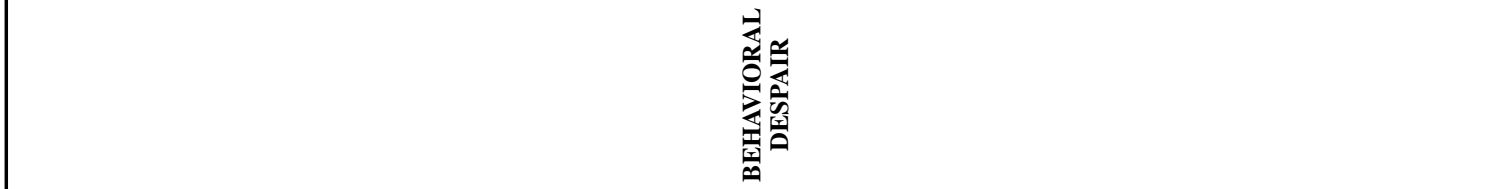 } \\
\hline
\end{tabular}

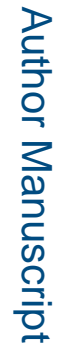

를 


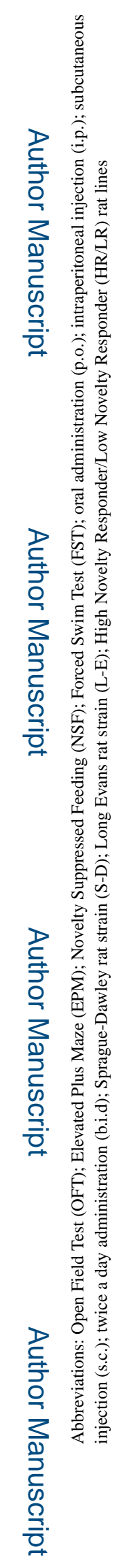

